\title{
Molecular linkage mapping and marker-trait associations with NIRPT, a downy mildew resistance gene in Nicotiana langsdorffii
}

\author{
Shouan Zhang ${ }^{\dagger \neq}$, Muqiang Gao and David Zaitlin ** \\ Kentucky Tobacco Research and Development Center, University of Kentucky, Lexington, KY, USA
}

\section{Edited by:}

Eric B. Holub, University of Warwick, United Kingdom

\section{Reviewed by:}

Christina Dixelius, Swedish University of Agricultural Sciences, Sweden

Dennis Halterman, United States

Department of Agriculture, USA

\section{${ }^{*}$ Correspondence:}

David Zaitlin, University of Kentucky, 1401 University Drives, Lexington, KY 40546-0236, USA.

e-mail: dzait2@uky.edu

\section{${ }^{\dagger}$ Current address:}

Shouan Zhang, Tropical Research and Education Center, The Institute of Food and Agricultural Sciences, University of Florida, 18905 South West 280th Street, Homestead, FL 33031, USA.

e-mail: szhang0007@ufl.edu

${ }^{\ddagger}$ Shouan Zhang and David Zaitlin have contributed equally to this work.

Nicotiana langsdorffii is one of two species of Nicotiana known to express an incompatible interaction with the oomycete Peronospora tabacina, the causal agent of tobacco blue mold disease. We previously showed that incompatibility is due to the hypersensitive response $(\mathrm{HR})$, and plants expressing the HR are resistant to P. tabacina at all stages of growth. Resistance is due to a single dominant gene in N. langsdorffii accession S-4-4 that we have named NIRPT. In further characterizing this unique host-pathogen interaction, NIRPT has been placed on a preliminary genetic map of the $N$. langsdorffii genome. Allelic scores for five classes of DNA markers were determined for 90 progeny of a "modified backcross" involving two $N$. langsdorffii inbred lines and the related species $N$. forgetiana. All markers had an expected segregation ratio of 1:1, and were scored in a common format. The map was constructed with JoinMap 3.0, and loci showing excessive transmission distortion were removed. The linkage map consists of 266 molecular marker loci defined by 217 amplified fragment length polymorphisms (AFLPS), 26 simple-sequence repeats (SSRs), 10 conserved orthologous sequence markers, nine inter-simple sequence repeat markers, and four target region amplification polymorphism markers arranged in 12 linkage groups with a combined length of $1062 \mathrm{cM}$. NIRPT is located on linkage group three, flanked by four AFLP markers and one SSR. Regions of skewed segregation were detected on LGs 1, 5, and 9. Markers developed for $N$. langsdorffii are potentially useful genetic tools for other species in Nicotiana section Alatae, as well as in N. benthamiana. We also investigated whether AFLPs could be used to infer genetic relationships within $N$. langsdorffii and related species from section Alatae. A phenetic analysis of the AFLP data showed that there are two main lineages within $N$. langsdorffii, and that both contain populations expressing dominant resistance to $P$. tabacina.

\section{Keywords: molecular markers, disease resistance, linkage mapping, AFLP, Nicotiana benthamiana}

\section{INTRODUCTION}

The downy mildews are a group of biotrophic oomycetes that form parasitic, often species-specific interactions with certain groups of angiosperms. Commonly known as water molds, oomycetes are spore-forming filamentous protists that superficially resemble fungi, but actually share a common evolutionary history with the photosynthetic chromophyte algae, a group that includes diatoms, brown algae, and giant kelps in the kingdom Stramenopila (Kamoun et al., 1999; Petersen and Rosendahl, 2000; Dick, 2002; Tyler et al., 2006). Many oomycete species are familiar plant and animal pathogens, and several have historically caused devastating agricultural disease epidemics that resulted in widespread human suffering and significant economic losses. Among the well-known examples of this are the Great Famine in Ireland (1845-1852) caused by the potato late blight pathogen (Phytophthora infestans), and the grape downy mildew (Plasmopara viticola) epidemic of 1878-1882 that nearly destroyed the French wine industry (Johnson, 1935; Ristaino, 2002). The genus Peronospora sensu latu (Peronosporales) is the largest genus of downy mildews; all species are obligately biotrophic parasites that, as a group, infect a broad range of dicot species (families such as Fabaceae, Chenopodiaceae, Rosaceae, Caryophyllaceae, Rubiaceae, Solanaceae, Papaveraceae, Euphorbiaceae etc.), as well as a single family of monocots, the Alliaceae. Molecular systematic treatments based on the nuclear ribosomal internal transcribed spacer region (nrITS, including the 5.8S rRNA gene) have shown Peronospora to be a monophyletic group closely related to Phytophthora (Cooke et al., 2002; Voglmayr, 2003), a genus that also contains many destructive plant pathogens. In addition, species parasitic on cruciferous hosts (including Hyaloperonospora; Slusarenko and Schlaich, 2003) were found to group together in a highly supported clade that was sister to all other species of Peronospora (Voglmayr, 2003). More recent phylogenetic analyses based on additional rDNA and gene sequence data (coding and non-coding) from more downy mildew taxa confirmed the previous results and provided an evolutionary scheme for 14 genera of the Peronosporales and its closest relative, Phytophthora (Göker et al., 2007).

Genetic resistance to phytopathogenic oomycetes is wellknown in dicotyledonous plants. There are many examples of single dominant genes conferring host resistance in major crop 
species, as well as in Arabidopsis, and some of these have been cloned and characterized (Mauch-Mani, 2002; Martin et al., 2003; Hein et al., 2009). Observed resistance phenotypes often involve the hypersensitive response (HR), a form of programmed cell death (PCD) in the host. In fact, the HR appears to be a common feature of host resistance to downy mildews and other oomycete pathogens in general (Kamoun et al., 1999; Vleeshouwers et al., 2000).

Wild relatives of crops such as lettuce, sunflower, tomato, and potato have proven to be valuable sources of genetic resistance to oomycete pathogens (Van Der Vossen et al., 2003; Lebeda et al., 2008; Wieckhorst et al., 2010). The most economically important of these genes provide resistance to late blight, caused by $P$. infestans, in commercial cultivars of potato (Solanum tuberosum). Resistance to $P$. infestans is known from at least eight wild potato species, with many of the single dominant genes for late blight resistance originating in two diploid species, Solanum bulbocastanum and S. demissum (Park et al., 2009). Similarly, WRR4, a dominant gene that conditions broad-spectrum resistance to important races of Albugo candida, was recently isolated and characterized from the model dicot Arabidopsis thaliana Col-0 (Borhan et al., 2008). A. candida is an obligately biotrophic oomycete pathogen that causes white blister rust on a number of species in the Brassicaceae. WRR4 has been demonstrated to confer full white rust resistance to single susceptible cultivars of $B$. napus and B. juncea (Borhan et al., 2010), and it is possible that this and other white rust R-genes from Arabidopsis will be incorporated into commercial Brassica crops that are susceptible to infection by A. candida.

Peronospora tabacina D.B. Adam (syn. P. hyoscyami de Bary) is the causal agent of blue mold disease, a major foliar disease of cultivated tobacco in many areas of the world where tobacco is grown. P. tabacina can infect all types of tobacco at all stages of growth and can spread rapidly under favorable weather conditions due to the polycyclic nature of this intimate host-pathogen association (Main, 1991). Historically, blue mold has been known in the US since 1921, when it first appeared in tobacco seedbeds in Georgia and Florida, although it took 10 years for it to become a persistent problem (Wolf, 1947). Due to the intensity of asexual sporangia production on infected plants, the potential for epidemic development, and associated crop damage, can be very high when optimal environmental conditions for pathogen growth and sporulation prevail. Fungicides are generally applied in an attempt to limit economic losses caused by blue mold infection. The systemic phenylamide fungicide metalaxyl (Ridomil ${ }^{\circledR}$; Syngenta Crop Protection, Greensboro, NC, USA), an inhibitor of rDNA synthesis, is effective for controlling P. tabacina in the field, and is also active against other foliar and soil-borne species of Phytophthora and Pythium in crops such as potato, grapes, and some ornamentals (Gisi, 2002). However, resistant strains of $P$. tabacina have developed in some countries as a result of excessive fungicide application (Wiglesworth et al., 1988; Main, 1991). Genetic resistance in the host (tobacco cultivars) would be the most economical and environmentally friendly means of controlling blue mold epidemics in the field.

Cultivated tobacco ( $N$. tabacum) is an excellent host for $P$. tabacina, and no naturally resistant variety or cultivar has been identified, despite an intensive search (Clayton, 1945; Julio et al., 2006b). A number of Australian species of Nicotiana are highly resistant to $P$. tabacina infection; quantitative, polygenic resistance to blue mold has been transferred into tobacco from species such as $N$. debneyi, and several partially resistant tobacco cultivars were released in Australia and the United States beginning in the 1960s (Clayton, 1967, 1968; Rufty et al., 1990). Natural sources of monogenic resistance to several other tobacco diseases have also been identified in undomesticated species of Nicotiana and transferred to cultivated tobacco. Examples are the $N$ gene for TMV resistance from N. glutinosa (Holmes, 1938; Dinesh-Kumar et al., 1995), the $P h$ gene for black shank resistance from N. plumbaginifolia (Johnson et al., 2002a), and monogenic dominant resistance to black root rot (Chalara elegans) from N. debneyi (Kenward et al., 1999). Host reactions to blue mold infection are dependent upon factors such as plant age, physiological status, and environmental conditions, and the results from field experiments can be highly variable and unpredictable. Thus, identification of molecular marker loci that are tightly linked to a blue mold resistance gene could be used to eliminate the susceptible individuals during early stages of a breeding program. Development of a molecular map would also make positional or map-based cloning of such resistance genes possible.

Molecular genetic markers have been developed for several species of Nicotiana, often with an emphasis on phylogenetic reconstruction and genetic distance estimation (Bogani et al., 1997; Yu and Lin, 1997; Ren and Timko, 2001; Julio et al., 2006b; Yang et al., 2007). In N. tabacum, PCR-based marker systems that do not rely on genomic sequence information have been widely used in both genetic studies and marker-assisted selection. Methods such as AFLP (Vos et al., 1995) and random amplified polymorphic DNA (RAPD), which employs short primers of arbitrary sequence (Williams et al., 1990), are well suited to marker discovery in species like tobacco that have large and complex genomes. RAPDs, often in concert with bulked segregant analysis (BSA; Michelmore et al., 1991), have been particularly useful for detecting marker loci linked to genes or genomic regions that confer resistance to tobacco diseases such as blue mold (Milla et al., 2005) and black root rot (Bai et al., 1995), both of which were introgressed into $N$. tabacum from $N$. debneyi, black shank resistance that originated in $N$. plumbaginifolia (Johnson et al., 2002a,b), and potato virus Y (PVY) resistance from N. africana (Lewis, 2005). AFLP markers closely linked to the tomato spotted wilt virus resistance locus from N. alata were identified by Moon and Nicholson (2007). A linkage map consisting of 171 restriction fragment length polymorphism (RFLP) and RAPD loci was constructed for the N. longiflora/N. plumbaginifolia genome by Lin et al. (2001). Partial molecular marker-based linkage maps for $N$. tabacum have also been reported by Nishi et al. (2003), who identified a quantitative trait loci (QTL) associated with bacterial wilt resistance, and by Julio et al. (2006a) in a study of QTL affecting a diverse variety of agronomic and smoking-related traits. A comprehensive linkage map of the N. tabacum genome, based on the segregation of 2317 simple-sequence repeat (SSR) markers in an $\mathrm{F}_{2}$ population, was recently published by Bindler et al. (2011). In addition, Wu et al. (2010) reported the construction of conserved ortholog set (COS)II- and SSR-based marker linkage maps for the 
N. tomentosiformis/N. otophora and N. acuminata (both $n=12$ ) genomes.

We previously reported the discovery and initial characterization of a necrotic lesion resistance response to $P$. tabacina infection in N. langsdorffii Weinm. (Solanaceae, Nicotiana section Alatae), a diploid South American relative of cultivated tobacco (N. tabacum L.). In this host-pathogen interaction, P. tabacina resistance is mediated by the HR, is expressed in seedlings as well as adult plants, and is due to the presence of a single dominant gene called NIRPT in the host (Zhang and Zaitlin, 2008). By using BSA, several AFLP markers were identified that showed close linkage to the NIRPT locus. The objectives of this study were to determine the feasibility of using amplification-based molecular markers (AFLP, SSR, CAPS, inter-simple sequence repeat (ISSR), target region amplification polymorphism (TRAP), SCAR, and COS) to develop a molecular linkage map of the $N$. langsdorffii genome, and to identify marker loci associated with NIRPT. Both of these objectives were met, and we present a preliminary molecular marker-based map of the N. langsdorffii genome that includes NIRPT. A longerterm goal of this project will be to use closely linked molecular markers to introduce NIRPT into tobacco cultivars as a potential strategy to control tobacco blue mold disease in the field. $N$. tabacum $(n=24)$ and $N$. langsdorffii $(n=9)$ are not closely related - they are classified in two different sections of the genus, sections Nicotiana and Alatae, respectively (Knapp et al., 2004). The two species are sexually incompatible, and gene transfer may therefore require a transgenic strategy. We were also able to use cluster analysis of AFLP data to understand the genetic relationships within a group of $N$. langsdorffi collections that differ in their reactions to $P$. tabacina.

\section{MATERIALS AND METHODS \\ PLANT MATERIAL AND POPULATION DEVELOPMENT}

Seeds of $N$. langsdorffii accessions S-4-1 through S-4-10 were obtained from various sources and are given in Table 1 of Zhang and Zaitlin (2008). Nicotiana alata PI\#555473 (KTRDC accession \#S-1-4), N. forgetiana PI\#555501 (KTRDC \#S-11-2), and N. longiflora PI\#555531 (KTRDC \#S-33-1) were from the USDA Tobacco Collection. N. longiflora (KTRDC\#S-33-5) was obtained from the IPK-Gatersleben as accession NIC44. MO-9, MO-10, and MO-11 are wild N. langsdorffii seed collections made in December 1999 in Santa Catarina state, Brazil, and were the gift of Dr. Tim Holtsford of the University of Missouri, Columbia (see Lee et al., 2008). MO-9 was found to be segregating for HR-mediated resistance to P. tabacina, and two sub-lines, designated MO-9R (resistant) and MO-9S (susceptible), were selected from plants grown from the original seed provided by the Holtsford lab. Seeds of an unknown species of Nicotiana collected near Caçapava do Sul in the state of Rio Grande do Sul, Brazil was the gift of Mr. Mauro Peixoto of Mogi das Cruzes, São Paulo, Brazil. Comparisons of mature plants grown from this seed for growth habit and floral and leaf characteristics with the description and illustration given in Goodspeed (1954) allowed us to identify it as N. bonariensis Lehmann, an uncommon member of $N$. section Alatae. The original source of $N$. alata (Jasmine tobacco), KTRDC accession \#S-1-1, is unknown.

$N$. langsdorffii accession S-4-1 is highly susceptible to infection and colonization by $P$. tabacina, while accession S-4-4 is characterized as being highly resistant, developing HR necrotic lesions 2 days after inoculation with the pathogen (Zhang and Zaitlin, 2008). Ninety-two progeny from the "modified backcross" population BC1-1 [(S-4-1 $\times$ S-4-4) $\mathrm{F}_{1} \times N$. forgetiana S-11-2] were used to construct the linkage map. For BSA, DNA from progeny of an $\mathrm{F}_{2}$ population (derived from the S-4-1 $\times \mathrm{S}-4-4 \mathrm{~F}_{1}$ ) was used to construct two susceptible ( $\mathrm{S}$ ) bulks. A description of the segregating populations, as well as methods for pathogen inoculation, disease ratings, and plant reactions are given in Zhang and Zaitlin (2008).

\section{DNA EXTRACTION}

Genomic DNA was prepared from expanding leaves of young plants using the DNeasy Plant Mini Kit (QIAGEN Inc., Valencia, CA, USA) according to the manufacturer's instructions, and was quantified with a NanoDrop ND-1000 spectrophotometer (NanoDrop Products, Wilmington, DE, USA).

\section{AFLP REACTIONS}

AFLP manipulations were performed as described by Vos et al. (1995) using an AFLP Core Reagent Kit from Invitrogen (Carlsbad, CA, USA). Fluorescent Eco +3 primers labeled at the $5^{\prime}$ end with the WellRed D2 dye (Beckman Coutler) were synthesized by Proligo LLC (Boulder, CO, USA). Unlabeled primers were purchased from Integrated DNA Technologies (Coralville, IA, USA). Genomic DNA samples $(\sim 0.2 \mu \mathrm{g})$ were digested with EcoRI and MseI at $37^{\circ} \mathrm{C}$ in a final volume of $25 \mu$ l. Following ligation of the EcoRI and MseI- specific adaptor sequences at $20^{\circ} \mathrm{C}$ overnight $(15 \mathrm{~h})$, the reactions were diluted 10 -fold with TE $(10 \mathrm{mM}$ Tris$\mathrm{HCl}, 0.1 \mathrm{mM}$ EDTA, pH 8.0). Pre-selective amplifications (PSAs) were performed in $25 \mu \mathrm{l}$ of $1 \times$ FailSafe "A" premix (Epicenter Biotechnologies, Madison, WI, USA) with E01 and M02 primers (with a single $3^{\prime}$ selective base) at $0.5 \mu \mathrm{M}$, Taq DNA polymerase (New England Biolabs, Beverly, MA, USA) at $1 \mathrm{U}$ per reaction, and $3 \mu \mathrm{l}$ of diluted ligation DNA for 22 cycles $\left(94^{\circ} \mathrm{C}\right.$ for $30 \mathrm{~s}, 56^{\circ} \mathrm{C}$ for $60 \mathrm{~s}$, and $72^{\circ} \mathrm{C}$ for $60 \mathrm{~s}$ ). The PSA reactions were examined by electrophoresis on a $1.5 \%$ agarose gel for the presence of a predictable band pattern before proceeding. For selective amplification (SA), PSA reactions were diluted 20 -fold in deionized water and amplified with $\mathrm{E}+3$ and $\mathrm{M}+3$ primers (three selective bases at the $3^{\prime}$ end) using a "touchdown" cycling program (Vos et al., 1995) consisting of an initial denaturation step of $94^{\circ} \mathrm{C}$ for $2 \mathrm{~min}$, followed by 10 cycles of $94^{\circ} \mathrm{C}$ for $20 \mathrm{~s}, 66^{\circ} \mathrm{C}$ for $30 \mathrm{~s}$, and $72^{\circ} \mathrm{C}$ for $2 \mathrm{~min}$ with the annealing temperature decreased by $1^{\circ} \mathrm{C} / \mathrm{cycle}$, and then 20 cycles of $94^{\circ} \mathrm{C}$ for $20 \mathrm{~s}, 56^{\circ} \mathrm{C}$ for $30 \mathrm{~s}$, and $72^{\circ} \mathrm{C}$ for $2 \mathrm{~min}$ with a final step of $30 \mathrm{~min}$ at $60^{\circ} \mathrm{C}$. In a total volume of $20 \mu \mathrm{l}$, each SA reaction contained $10 \mu \mathrm{l}$ FailSafe "A" premix (Epicenter), 1.5 pmol dye-labeled $\mathrm{E}+3$ primer, $6.25 \mathrm{pmol}$ unlabeled $\mathrm{M}+3$ primer, $1 \mathrm{U}$ Taq DNA polymerase, and $4 \mu \mathrm{l}$ of diluted PSA DNA. All DNA amplifications were performed in an iCycler Thermal Cycler (Bio-Rad Laboratories, Hercules, CA, USA). Following amplification, SAs were diluted 30-fold into Sample Loading Solution (SLS; Beckman Coutler, Fullerton, CA, USA) containing a 100-fold dilution of DNA Size Standard-600 (Beckman Coulter). Amplified fragments were separated by capillary electrophoresis on an automatic DNA sequencing instrument (Beckman Coulter CEQ8000 Genetic Analysis System) using the Frag-4 method. For 
Table 1 | AFLP primers used for bulked segregant analysis (BSA), genetic linkage mapping, and cluster analysis in $\mathbf{N}$. langsdorffii.

\begin{tabular}{ll}
\hline AFLP primer ${ }^{\mathbf{1}}$ & DNA sequence $\mathbf{( 5}^{\prime} \boldsymbol{\rightarrow} \mathbf{3}^{\prime} \mathbf{)}$ \\
\hline E01 & AGACTGCGTACCAATTCA \\
M02 & GATGAGTCCTGAGTAAC \\
E32 & GACTGCGTACCAATTCAAC \\
E33 & GACTGCGTACCAATTCAAG \\
E36 & GACTGCGTACCAATTCACC \\
E39 & GACTGCGTACCAATTCAGA \\
E40 & GACTGCGTACCAATTCAGC \\
E41 & GACTGCGTACCAATTCAGG \\
M47 & GATGAGTCCTGAGTAACAA \\
M48 & GATGAGTCCTGAGTAACAC \\
M49 & GATGAGTCCTGAGTAACAG \\
M50 & GATGAGTCCTGAGTAACAT \\
M51 & GATGAGTCCTGAGTAACCA \\
M52 & GATGAGTCCTGAGTAACCC \\
M53 & GATGAGTCCTGAGTAACCG \\
M54 & GATGAGTCCTGAGTAACCT \\
M55 & GATGAGTCCTGAGTAACGA \\
M56 & GATGAGTCCTGAGTAACGC \\
M57 & GATGAGTCCTGAGTAACGG \\
M58 & GATGAGTCCTGAGTAACGT \\
M59 & GATGAGTCCTGAGTAACTA \\
M60 & GATGAGTCCTGAGTAACTC \\
M61 & GATGAGTCCTGAGTAAGTG \\
M62 & GATGAGTCCTGAGTAAGTT \\
\hline
\end{tabular}

'All " $E$ " primers were labeled at the 5' end with WellRed D2 dye for fluorescent detection.

each primer combination, sample order was randomized on the CEQ8000 to avoid any positional effects due to potential variations in the individual capillaries. The AFLP primers used are shown in Table 1. Primer nomenclature is from KeyGene N.V. ${ }^{1}$.

\section{AFLP DATA ANALYSIS}

DNA fragment peak sizes in the D2 channel were calculated (in nucleotide bases) against the standards (60-640 bases) in the D1 channel using the software supplied with the CEQ8000 (Beckman Coulter). In our hands, the quartic equation gave the best approximation of a linear relationship between peak size and migration time with the 600 standard. For genotypic cluster analysis, fluorescent peaks were machine scored $(1=$ present, $0=$ absent $)$ using the "New AFLP Analysis" module (parameter settings: $15 \%$ slope threshold, 5\% relative peak height threshold, 95\% confidence level, bin width $=1 \mathrm{bp}$ ) and the data was exported to Microsoft Excel. Every AFLP chromatogram was examined for the presence of unscored peaks at a minimum height threshold of 500 fluorescence units. Data entries from poorly resolved and miscalled peaks were manually removed from the spreadsheets. Bins containing peaks outside of the standard size range $(<60$ and $>640$ bases) were eliminated. All manual scoring was performed by the same individual to ensure consistency.

${ }^{1}$ http://www.keygene.com/home/index.php

\section{BULKED SEGREGANT ANALYSIS AND AFLP MARKERS}

Two DNA bulks (S\#1 and S\#2) were prepared by pooling approximately equal amounts of total DNA from 12 and 15 blue mold susceptible $\mathrm{F}_{2}$ progeny plants, respectively, that were selected based on their responses to blue mold infection (Table 3 in Zhang and Zaitlin, 2008). Pooled DNA samples to be used for amplification were adjusted to a concentration of $100 \mathrm{ng} / \mu \mathrm{l}$, and $500 \mathrm{ng}$ of each was double digested with $E c o$ RI and $M s e I$ and prepared for AFLP analysis as described above. The $\mathrm{S} \# 1$ and $\mathrm{S} \# 2$ bulks, the two $N$. langsdorffii inbred lines (S-4-1 and S-4-4), the $\mathrm{F}_{1}$ parent (S-4$1 \times$ S-4-4), and $N$. forgetiana S-11-2 were screened with a total of 46 AFLP primer pairs (Tables 1 and 2) in an effort to identify amplified peaks showing an association with the NIRPT gene. Based on evaluations of these six DNA samples, 92 individuals from the modified BC population, the three parental accessions (S-4-1, S-4-4, and S-11-2), and the $\mathrm{F}_{1}$ were subjected to fluorescent AFLP analysis as described above with 14 pre-screened primer pair combinations (E32M47, E32M60, E33M58, E32M62, E33M48, E39M51, E39M52, E39M55, E39M59, E39M60, E40M50, E40M60, E41M48, and E41M50).

\section{SIMPLE-SEQUENCE REPEAT MARKERS}

Genomic DNA of $N$. langsdorffii S-4-5, purified on a CsTFA gradient (Zhang et al., 2003), was provided to Genetic Identification Systems (GIS; Chatsworth, CA, USA) for the construction of plasmid-based genomic libraries enriched in DNA fragments containing di-, tri-, or tetranucleotide repeat sequences. Four such libraries, selected independently for CA/TG, GA/TC, AAC/GTT, and TAGA/TCTA repeats (libraries A, B, C, and D, respectively), were delivered in under 5 weeks from receipt of the DNA. DNA sequencing of several dozen plasmid clones was performed at GIS and KTRDC, but the majority (282) were sequenced at the University of Kentucky Advanced Genetics Technology Center. We were able to design oligonucleotide primers flanking the repeated sequence blocks for 98 SSR containing clones using Primer3 v. 0.4. $0^{2}$. All primers were purchased from $\mathrm{IDT}^{3}$ (Coralville, IA, USA).

To identify polymorphic SSR markers, each primer pair was screened for amplification over a set of seven Nicotiana genotypes that included two accessions each of N. langsdorffii, N. alata, and $N$. longiflora, and N. forgetiana S-11-2. Amplified fragments were visualized and sized electrophoretically on gels made of $2 \%$ (w/v) MetaPhor ${ }^{\circledR}$ agarose (Cambrex Bio Science Rockland, Inc., Rockland, ME, USA) in $0.5 \times$ Tris-borate EDTA buffer (Amresco, Solon, OH, USA) containing $0.5 \mu \mathrm{g} / \mathrm{ml}$ ethidium bromide. Primer sequences and amplification conditions for the 29 SSR markers used here are given in Table 3.

\section{CONSERVED ORTHOLOG SET MARKERS}

Primer sequences for 51 COSII markers (Fulton et al., 2002; Mueller et al., 2005; Wu et al., 2006) previously mapped in tomato were obtained from the SOL Genomics Network (SGN) website $^{4}$, and the oligonucleotides were synthesized by IDT. In all

\footnotetext{
${ }^{2}$ http://frodo.wi.mit.edu

${ }^{3} \mathrm{http}: / /$ eu.idtdna.com/site

${ }^{4} \mathrm{http}: / /$ solgenomics.net
} 
Table 2 | AFLP primer pairs used in BSA screening for linkage to the R-gene NIRPT.

\begin{tabular}{|c|c|}
\hline AFLP primer pair & AFLPs linked to NIRPT \\
\hline E32M47 & None detected \\
\hline E32M48 & None detected \\
\hline E32M56 & None detected \\
\hline E32M57 & None detected \\
\hline E32M58 & None detected \\
\hline E32M60 & None detected \\
\hline E32M62 & E32M62_177 \\
\hline E33M48 & E33M48_292 \\
\hline E33M52 & None detected \\
\hline E33M54 & None detected \\
\hline E33M55 & None detected \\
\hline E33M56 & None detected \\
\hline E33M58 & None detected \\
\hline E33M59 & None detected \\
\hline E33M60 & None detected \\
\hline E33M62 & None detected \\
\hline E36M47 & None detected \\
\hline E36M49 & E36M49_261 \\
\hline E36M50 & None detected \\
\hline E36M51 & None detected \\
\hline E36M62 & None detected \\
\hline E39M48 & None detected \\
\hline E39M50 & None detected \\
\hline E39M51 & E39M51_224 \\
\hline E39M52 & None detected \\
\hline E39M54 & None detected \\
\hline E39M55 & E39M55_129 \\
\hline E39M56 & None detected \\
\hline E39M59 & None detected \\
\hline E39M60 & None detected \\
\hline E40M47 & None detected \\
\hline E40M49 & None detected \\
\hline E40M50 & None detected \\
\hline E40M51 & None detected \\
\hline E40M53 & None detected \\
\hline E40M54 & None detected \\
\hline E40M60 & None detected \\
\hline E40M61 & None detected \\
\hline E41M47 & None detected \\
\hline E41M48 & None detected \\
\hline E41M50 & E41M50_198 \\
\hline E41M52 & None detected \\
\hline E41M55 & None detected \\
\hline E41M56 & None detected \\
\hline E41M58 & None detected \\
\hline E41M60 & None detected \\
\hline
\end{tabular}

cases, primer pairs were screened for amplification against a panel of six genomic DNA samples; N. obtusifolia PI555573, N. benthamiana, Roma tomato, N. langsdorffii S-4-1 and S-4-4, and N. forgetiana S-11-2. We used a single PCR regimen and assayed each primer pair in both FailSafe pre-mixes "A" and "D" (a total of 12 amplifications per screening panel). Twenty-one primer pairs
Table 3 | Primers for SSR marker amplification in Nicotiana spp., the NIRPT mapping population, and $N$. benthamiana* .

\begin{tabular}{|c|c|c|c|}
\hline Locus name & & $T_{\text {anneal }}\left({ }^{\circ} \mathrm{C}\right)$ & DNA sequence $\left(5^{\prime} \rightarrow 3^{\prime}\right)$ \\
\hline \multirow[t]{2}{*}{ GIS_A4* } & $\mathrm{F}$ & 55 & TGCGCCAGTCAAATTCATACG \\
\hline & $\mathrm{R}$ & & GGAGTCCGCAAGAGAGGAATA \\
\hline \multirow[t]{2}{*}{ GIS_A6 } & $\mathrm{F}$ & 54 & TGGTGAAACAGTTGCCACAT \\
\hline & $\mathrm{R}$ & & AGTCGCCTCAAGACTGAAACA \\
\hline \multirow[t]{2}{*}{ GIS_A9 } & $\mathrm{F}$ & 53 & AACCCATGACAACGCATACA \\
\hline & $\mathrm{R}$ & & TGGTCTATTTGCCACGTGAA \\
\hline \multirow[t]{2}{*}{ GIS_B3* } & $\mathrm{F}$ & 55 & AGTCTATGCGAGGGGACCTT \\
\hline & $\mathrm{R}$ & & TTGGTCCTGTGACTCCAACA \\
\hline \multirow[t]{2}{*}{ GIS_C12* } & $\mathrm{F}$ & 53 & AAGAAATGGACAAACCAACTGC \\
\hline & $\mathrm{R}$ & & СCTTGTTTGGGACTGAAACGTA \\
\hline \multirow[t]{2}{*}{ GIS_D1* } & $\mathrm{F}$ & 54 & GATGCAGACCAGTTGCTGAA \\
\hline & $\mathrm{R}$ & & TCAACCAACGCTGCAAGTAG \\
\hline \multirow[t]{2}{*}{ GIS_D3 } & $\mathrm{F}$ & 52 & GCAGTTGTATATTTGAAAGCCAAA \\
\hline & $\mathrm{R}$ & & TGCTGAAGGGTTAGATGTTCC \\
\hline \multirow[t]{2}{*}{ GIS_D7 } & $\mathrm{F}$ & 52 & TCTTTTGGGCTTTCCACTTTTAA \\
\hline & $\mathrm{R}$ & & CTCGTGCCACAATATCATCAAT \\
\hline \multirow[t]{2}{*}{ KTRDC_B3 } & $\mathrm{F}$ & 54 & GTGCAAACTGAACTGGCTGAC \\
\hline & $\mathrm{R}$ & & TCAACATGGCTCGATAGATGG \\
\hline \multirow[t]{2}{*}{ KTRDC_B4 } & $\mathrm{F}$ & 53 & TATGGCAATGTGCTTTGTATGC \\
\hline & $\mathrm{R}$ & & TGCCATCATGAGATGTTTTTCA \\
\hline \multirow[t]{2}{*}{ KTRDC_B5* } & $\mathrm{F}$ & 53 & CAAGCCATCCCATCTCCATA \\
\hline & $\mathrm{R}$ & & GCCAGTGAGGACAAACGAGT \\
\hline \multirow[t]{2}{*}{ A104 } & $\mathrm{F}$ & 54 & GGACAAAGTTAAGCCTACCCC \\
\hline & $\mathrm{R}$ & & GGACTCCAATCGCTGTATCAA \\
\hline \multirow[t]{2}{*}{$\mathrm{A} 112^{*}$} & $\mathrm{~F}$ & 50 & CAATTACGATTTCTTTCCATCG \\
\hline & $\mathrm{R}$ & & AAGTCACCTTGTTTGGTGTACG \\
\hline \multirow[t]{2}{*}{ A113* } & $\mathrm{F}$ & 53 & GGACCATCTCAACAAAGATATGC \\
\hline & $\mathrm{R}$ & & TGTTACAGTTTTGTGGTTTAGGG \\
\hline \multirow[t]{2}{*}{ A118* } & $\mathrm{F}$ & 53 & GCATTTTTCCCAAGAGACAGACTA \\
\hline & $\mathrm{R}$ & & YTGGAAAGAAAAGAAGATGAGCA \\
\hline \multirow[t]{2}{*}{ A152 } & $\mathrm{F}$ & 56 & TCCACAGCACAGACCCTTTACT \\
\hline & $\mathrm{R}$ & & CTCACACACAAACACACACACG \\
\hline \multirow[t]{2}{*}{ A154 } & $\mathrm{F}$ & 54 & TATCACCAACGCACTCATCTC \\
\hline & $\mathrm{R}$ & & AGTCAGGCTTGTCAGCTCATT \\
\hline \multirow[t]{2}{*}{ A159* } & $\mathrm{F}$ & 52 & CCCATAAAATTGGGGCCTTA \\
\hline & $\mathrm{R}$ & & TGGAGTTGATGGTTGTTCCTG \\
\hline \multirow[t]{2}{*}{ A160 } & $\mathrm{F}$ & 55 & ATGACGAGTGCCTGAGTCCTA \\
\hline & $\mathrm{R}$ & & GCGTGTGACCTTATCAGCTTC \\
\hline \multirow[t]{2}{*}{$\mathrm{A} 161^{*}$} & $\mathrm{~F}$ & 53 & CCGCTAGTTGAATCCTCAATTCT \\
\hline & $\mathrm{R}$ & & TGATATGATTACCCCTGGTGTTG \\
\hline \multirow[t]{2}{*}{ A172 } & $\mathrm{F}$ & 53 & CACGTATTTGCCTGCCTAACA \\
\hline & $\mathrm{R}$ & & CAAGGTCCCATATTGGGCTAA \\
\hline A204* & $\mathrm{F}$ & 54 & CTTGGTCAACGGGTTCATCT \\
\hline & $\mathrm{R}$ & & ATGTGGAACTGCGGTTATGC \\
\hline A207 & $\mathrm{F}$ & 53 & TATTTCACCCACAGCCTTCTT \\
\hline & $\mathrm{R}$ & & GTGTTCACCTGTGCCAATTAAA \\
\hline $\mathrm{A} 218^{*}$ & $\mathrm{~F}$ & 54 & TCGGCCTCACAGCAATAATC \\
\hline & $\mathrm{R}$ & & СTCATCTCCCAGGCCCTAAA \\
\hline A224* & $\mathrm{F}$ & 55 & CAGAGGATCATGCGACCACT \\
\hline & $\mathrm{R}$ & & CCGCCTCTTGCACAAAGTAG \\
\hline B151 & $\mathrm{F}$ & 54 & ССТTСССТАСТСААGTTTСАATGT \\
\hline & $\mathrm{R}$ & & AAACAGAGAACGCCAAATGGA \\
\hline
\end{tabular}

(Continued) 
Table 3 | Continued

\begin{tabular}{|c|c|c|c|}
\hline Locus name & & $T_{\text {anneal }}\left({ }^{\circ} \mathrm{C}\right)$ & DNA sequence $\left(5^{\prime} \rightarrow 3^{\prime}\right)$ \\
\hline \multirow[t]{2}{*}{ B155* } & $\mathrm{F}$ & 55 & GTCGAGAGGGCTAAGTGAACAA \\
\hline & $\mathrm{R}$ & & ACAAGTCATCGACACGCGACAA \\
\hline \multirow[t]{2}{*}{ B158 } & $\mathrm{F}$ & 54 & AAGCCTTTTTCTTTTTTGAGGGACT \\
\hline & $\mathrm{R}$ & & СТTCAАТСТTСАААССАССАСТG \\
\hline \multirow[t]{2}{*}{ B162* } & $\mathrm{F}$ & 55 & TGAGAAGGGGAAAAGGAGGTT \\
\hline & $\mathrm{R}$ & & TACTCTCAGCGAGGTGACGAA \\
\hline \multirow[t]{2}{*}{ B202* } & $\mathrm{F}$ & 52 & CAAGGTCTGCTATTGTGAGTG \\
\hline & $\mathrm{R}$ & & CACCAGTGTTCCACGTAAAGAA \\
\hline \multirow[t]{2}{*}{$\mathrm{B} 211^{*}$} & $\mathrm{~F}$ & 54 & TGCTGTTGCAAGGTCTGCTAT \\
\hline & $\mathrm{R}$ & & AAATCTGGAGTGCCCAATGTC \\
\hline \multirow[t]{2}{*}{ B215* } & $\mathrm{F}$ & 55 & CCCAGTCTCCTTAGCCATCTG \\
\hline & $\mathrm{R}$ & & AGGGCAGCATATCCGCTACT \\
\hline \multirow[t]{2}{*}{ C156* } & $\mathrm{F}$ & 53 & CACAATATCCTGCCCATACCC \\
\hline & $\mathrm{R}$ & & GAAGAAATTCCCGGCTTCAC \\
\hline \multirow[t]{2}{*}{ C157 } & $\mathrm{F}$ & 53 & TCACTATTCTTGAGCCGAGGA \\
\hline & $\mathrm{R}$ & & GTCATTCCTGTCGATTGATGC \\
\hline \multirow[t]{2}{*}{ C161 } & $\mathrm{F}$ & 53 & TCACAAGATGGAACAGTACATGC \\
\hline & $\mathrm{R}$ & & TCCAAAGACTTTTGTAGTGGTGA \\
\hline \multirow[t]{2}{*}{ C167 } & $\mathrm{F}$ & 54 & CCTTGAGCCGAGGGTCTATT \\
\hline & $\mathrm{R}$ & & GGGCAGGCAATTGAGATACA \\
\hline \multirow[t]{2}{*}{$\mathrm{C} 202^{*}$} & $\mathrm{~F}$ & 54 & TGGGATCACACTGGGTATGT \\
\hline & $\mathrm{R}$ & & TCCATTCGGGTTACCTTTTCC \\
\hline \multirow[t]{2}{*}{ D152 } & $\mathrm{F}$ & 53 & GCGAACGACATTTCGCTAAG \\
\hline & $\mathrm{R}$ & & ATAGGGAACACGCGCAACAT \\
\hline \multirow[t]{2}{*}{ D159 } & $\mathrm{F}$ & 54 & AATACCGAACCGAAATACCGAAT \\
\hline & $\mathrm{R}$ & & AAGCGAACGACATTTGACTAAGG \\
\hline \multirow[t]{2}{*}{ D161 } & $\mathrm{F}$ & 54 & GATGCAGACCAGTTGCTGAA \\
\hline & $\mathrm{R}$ & & TCAACCAACGCTGCAAGTAG \\
\hline \multirow[t]{2}{*}{ D171 } & $\mathrm{F}$ & 54 & TCGCATGAAAGAGACCTCGTA \\
\hline & $\mathrm{R}$ & & CTCCGAAGGAACACATCCATT \\
\hline
\end{tabular}

directed amplification of a discreet fragment from at least one of the species assayed. Those that gave single fragments from S-4-1, S-4-4, and S-11-2 were subjected to further evaluation as CAPS markers (Konieczny and Ausubel, 1993). The fragments from the three parental accessions were individually digested with up to 12 restriction endonucleases (AluI, AvaI, BfaI, DpnII, HaeIII, HinfI, HinP1I, MseI, MspI, RsaI, ScrF1I, and TaqI) in an attempt to identify an enzyme that allowed us to unambiguously distinguish the S-4-1 and S-4-4 allelic fragments from one another, without interference from the S-11-2 PCR product. Primer sequences for the COSII markers and the restriction enzymes used in this study are given in Table 4.

\section{ISSR AND SCAR MARKERS}

The two N. langsdorffii genotypes (S-4-1 and S-4-4) and N. forgetiana S-11-2 were screened with 7 ISSR primers (UBC817, 819, $825,826,827,849$, and 850) from the University of British Columbia set \#9 (see Sankar and Moore, 2001) for amplified bands that were unique to either of the $N$. langsdorffi parents and also absent in N. forgetiana. We observed that some ISSR fragments amplified inconsistently in the mapping population. Consequently, ten DNA fragments (five generated with UBC826 and five generated with UBC827) were purified by agarose gel electrophoresis and cloned into pGEM-T (Promega). The recombinant plasmids were digested with BstZI (Promega) to size the inserted DNA fragments, and selected plasmids were subjected to DNA sequencing. The original ISSR primers (17 bases in length) were converted to SCAR (sequence characterized amplified region) marker primers by extending the $3^{\prime}$ ends with 4-7 selective bases (Albani et al., 2004). The SCAR primer sequences are given in Table 4.

\section{SRAP AND TRAP MARKERS}

Target region amplification polymorphism markers (Hu and Vick, 2003) were amplified using the gene-specific primer NBS9, labeled at the $5^{\prime}$ end to enable fluorescent detection, and unlabeled random primers from Li and Quiros (2001). NBS9 was designed to be complementary to the conserved GLPL motif of the nucleotide binding site domain found in many plant R-genes (Wang et al., 2008). Amplification reactions $(20 \mu \mathrm{l})$ contained $1 \times$ FailSafe "A" premix (Epicenter), $10 \mathrm{pmol}$ of each primer, and $\sim 50 \mathrm{ng}$ genomic DNA. Amplification parameters were the same as given for SRAP markers (Li and Quiros, 2001).

\section{DATA SCORING AND LINKAGE ANALYSIS}

The segregating population (which we have called a "modified" $\mathrm{BC}_{1}$ ) was designed so that all polymorphic markers, regardless of type (AFLP, SSR, COS, CAPS, etc.) could be scored using a single common format; the S-4-1 allele was designated "a" and the S-4-4 allele was designated " $b$ " for each segregating locus. Allelic data scores for each individual were entered manually into a spreadsheet, which was then converted to a simple text file for analysis by JoinMap 3.0 (licensed copy provided by H. Zhu). The data was analyzed using the following parameters: HAP1 population type; maximum recombination frequency of 0.45 ; initial LOD threshold of 4.0 for the identification of linkage groups (LGs); LOD threshold of 6.0 for the final linkage group determination. The Haldane mapping function was employed. Graphical maps were generated with MapChart version 2.2 (Voorrips, 2002) from text files exported from JoinMap.

\section{CLUSTER ANALYSIS OF $\boldsymbol{N}$. LANGSDORFFII ACCESSIONS}

Fluorescent AFLP peak data was collected for 14 accessions of $N$. langsdorffi, and a single accession each of N. alata, N. forgetiana, N. longiflora, and $N$. bonariensis. We used six AFLP primer pairs $(\mathrm{E}+3 / \mathrm{M}+3)$, which gave a total of 1300 unique fragment bins for the set of 18 entries. A dissimilarity matrix was calculated using NTSYSpc 2.2 (SIMINT with the DIST option selected; Rohlf, 2007) so that the AFLP data could be clustered using the Neighbor-Joining (N-J) algorithm (Saitou and Nei, 1987; Kim et al., 2004). Bootstrap analysis was also performed with NTSYSpc 2.2 by using the program modules RESAMPLE to generate 1000 resampled files of the AFLP data, SIMINT to calculate the distance matrices, NJOIN to calculate the N-J trees, and CONSENS (with MAJRUL enabled) to compare the trees and calculate the cluster frequencies. The cophenetic correlation coefficient $(r=0.96086$, normalized Mantel statistic $z$ ) was calculated using the COPH and MXCOMP modules in NTSYSpc. Principal coordinates analysis (PCoA) was also performed using the statistical software package MVSP 3.2 (Kovach Computing Services, Anglesey, Wales, 
Table 4 | Primers used for PCR amplification of COSII, SCAR, ISSR, and TRAP markers in N. langsdorffii.

\begin{tabular}{|c|c|c|c|c|c|}
\hline Marker locus & Type & & $T_{\text {anneal }}\left({ }^{\circ} \mathrm{C}\right)$ & Restriction enzyme & DNA sequence $\left(5^{\prime} \rightarrow 3^{\prime}\right)$ \\
\hline \multirow[t]{2}{*}{ At1g02140 } & cosII & $\mathrm{F}$ & 55 & $\mathrm{HinFI}$ & TCCGTTATGCTAACAATTCCAAC \\
\hline & & $\mathrm{R}$ & & & TGTGTTCATTTCCCATCACAATCTC \\
\hline & & $\mathrm{R}$ & & & TCTCTCCACAGCAGCACTGAAAGG \\
\hline At1g60640 & cosII & $\mathrm{F}$ & 53 & Dpnll & TCTGACAGGGGGAAATGAATCTTC \\
\hline & & $\mathrm{R}$ & & & TCCTAAAGTGCTCTCTGATAAGCTCT \\
\hline \multirow[t]{2}{*}{ At3g10220 } & cosII & $\mathrm{F}$ & 54 & None & TGGCTTCTCAGTTACAGATTCAAGG \\
\hline & & $\mathrm{R}$ & & & AACCTCCGGAGGTCACTGACG \\
\hline \multirow[t]{2}{*}{ At4g21520 } & cosil & $\mathrm{F}$ & 52 & None & TGACGGGGAGTCTGTATATGACTATTG \\
\hline & & $\mathrm{R}$ & & & TGATTGCCCTTCTTTATTTCCTTG \\
\hline \multirow[t]{2}{*}{ At5g64350 } & cosı & $\mathrm{F}$ & 53 & Aval & AGATCGGCCAAGGCAAAGTTATC \\
\hline & & $\mathrm{R}$ & & & TGCATGCCCAGTACTCCTTCATCC \\
\hline UBC825 & ISSR & & 49 & None & ACACACACACACACACT \\
\hline UBC826 & ISSR & & 51 & None & ACACACACACACACACC \\
\hline \multirow[t]{2}{*}{ U826_900 } & SCAR & $\mathrm{F}$ & 53 & None & ACACACACACACACACCAAAAGG \\
\hline & & $\mathrm{R}$ & & & ACACACACACACACACСАСТСТС \\
\hline \multirow[t]{2}{*}{ U826_1400 } & SCAR & $\mathrm{F}$ & 54 & Dpnll & ACACACACACACACCCAGATTG \\
\hline & & $\mathrm{R}$ & & & ACACACACACACACACCAGAAC \\
\hline \multirow[t]{2}{*}{ U826_1900 } & SCAR & $\mathrm{F}$ & 55 & None & ACACACACACACACACCGTGT \\
\hline & & $\mathrm{R}$ & & & ACACACACACACACACCAAAAAA \\
\hline NBS91 & TRAP & & 50 & & TGTGGAGGRTTACCTCTAGC \\
\hline
\end{tabular}

${ }^{1}$ Primer labeled with WellRed dye D3 at the 5 ' end to enable fluorescent detection.

UK). AFLP data was imported in spreadsheet format, and the following program settings were used; data matrix transformed, Euclidean distances computed, eigenanalysis tolerance set to $10^{-7}$. The resulting graphs were exported as enhanced metafiles, and text labels were added with the program Metafile Companion (Companion Software, Sunderland, MA, USA).

\section{RESULTS}

\section{SEGREGATING POPULATION STRUCTURE AND MARKER DEVELOPMENT}

In our N. langsdorffii population BC1-1 (the modified backcross), necrotic lesion resistance to $P$. tabacina infection segregated in the expected 1:1 ratio (Zhang and Zaitlin, 2008). Ninety-two individuals from this progeny set were chosen at random to constitute the genetic mapping population. All molecular markers used in this study were PCR-based, and, with the exception of the COS markers, were developed specifically for $N$. langsdorffii. Of the 98 SSR primer pairs designed from the genomic clones, 89 gave amplification products in at least one of the species of Nicotiana assayed, and 30 gave amplification products that differed in length between N. langsdorffii S-4-1 and S-4-4. Eleven of the SSR primer pairs gave amplification products only in N. langsdorffii, and five of these only gave a product from S-4-1 genomic DNA (S-4-1 is very similar to S-4-5, which was the DNA source used in the SSR enrichment). Fifty-nine of the SSR primer pairs gave amplification products from $N$. alata DNA, and 13 of these were polymorphic between the two accessions screened (S-1-1 and S-1-4). Similarly, 58 primer pairs directed amplification from genomic DNA of $N$. longiflora, and 20 gave length polymorphisms between accessions S-33-1 and S-33-5.

\section{IDENTIFICATION OF AFLP MARKERS LINKED TO NLRPT}

$N I R P T$ is a dominant gene, and we did not observe an intermediate resistance phenotype in the $\mathrm{F}_{1}(\mathrm{~S}-4-1 \times \mathrm{S}-4-4)$. Because of this, we could not distinguish $\mathrm{F}_{2}$ progeny plants that were homozygous at this locus $(N I R P T / N l R P T)$ from those that were heterozygous $(N l R P T / n l r p t)$ by their disease resistance phenotypes. Following inoculation with $P$. tabacina sporangia, necrotic lesions developed at the infection sites at 48 hpi on all plants expressing blue mold resistance. Therefore, we could not use a resistant bulk for the AFLP marker screening. We screened two independent susceptible $\mathrm{F}_{2}$ bulks (S\#1 and S\#2) with 46 AFLP primer pairs to identify peaks that showed linkage to NIRPT. We examined peaks in approximately 4500 size bins, and found five peaks produced by five different primer pairs that met the following criteria: they were 
present in the resistant parent S-4-4 and the $\mathrm{F}_{1}$ but were absent in susceptible parent S-4-1, the S\#1 and S\#2 bulks, and N. forgetiana S-11-2. The identified peaks were E32M62_177, E33M48_292, E39M51_224, E39M55_129, and E36M49_261. AFLP nomenclature followed that of Jeuken et al. (2001), where marker names were determined by the primer pair abbreviation (Table 1) followed by the calculated size of the fluorescent peak in nucleotides.

\section{LINKAGE MAP CONSTRUCTION}

In our mapping population, we obtained allelic scores for $320 \mathrm{~mol}-$ ecular markers that were polymorphic between S-4-1 and S-4-4. The population was structured so that all markers could be scored in the same manner with the expectation of a 1:1 allelic segregation ratio. AFLP, ISSR, and TRAP markers give amplification products from only one of the N. langsdorffii parents, and are analogous to genetic loci with dominant effects. Thus, we scored both the apparent (amplified) alleles and the null alleles for these markers. The progeny segregating for $P$. tabacina resistance came from the cross $\left[\left(\mathrm{A}_{1} \times \mathrm{A}_{2}\right) \times \mathrm{B}\right]$, where $\mathrm{A}$ is $N$. langsdorffii $(1=\mathrm{S}-4-1$ and $2=\mathrm{S}-4-4)$ and $\mathrm{B}$ is $N$. forgetiana S-11-2. We scored marker alleles that were present in $N$. langsdorffii but absent in $N$. forgetiana. Because chromosomal assortment and inter-locus recombination occurred in the $N$. langsdorffii $\mathrm{F}_{1}$ parent $\left(\mathrm{A}_{1} \times \mathrm{A}_{2}\right)$, the mapping progeny are genetically equivalent to a first generation backcross even though they are technically $\mathrm{F}_{1}$ hybrids between $N$. langsdorffii and $N$. forgetiana. Data analysis and map construction were performed with JoinMap 3.0 (Van Ooijen and Voorrips, 2001). Of the original 92 progeny, two (\#s 18 and 39) were eliminated because fewer than $80 \%$ of the markers were scored in these individuals. The final data set consisted of 28,101 allelic scores from 90 individuals $(2.43 \%$ missing data). The data for 29 AFLP loci that showed significant deviation from the expected 1:1 segregation ratio were eliminated from the analysis.

The resulting map of the $N$. langsdorffii genome is shown in Figure 1. JoinMap grouped 266 molecular marker loci and the resistance gene NlRPT into 12 LGs. The LGs ranged from 38 to $158 \mathrm{cM}$ in length, with a cumulative length of $1062 \mathrm{cM}$. A LOD threshold of 6.0 was used to calculate all LGs with the exception of LG5; reducing the LOD threshold to 5.0 resulted in the inclusion of a linked group of six additional loci, and maximized the length of this LG. Locus nomenclature for Figure 1 is as follows: amplified fragment length polymorphisms (AFLPs) - primer combination (ExxMxx) followed by the fragment size in nucleotide bases; SSRs all start with A, B, C, D, GIS, or KTRDC; COSII markers - AtXg followed by a five digit number; ISSR loci-U825 or U826 followed by a three digit number indicating the size of the mapped fragment in bases; ISSR/SCAR markers have a similar format, with the cloned fragment size indicated as a four digit number, followed by the size of the scored fragment if different (e.g., U826_1900/700); TRAP loci - gene-specific primer+random primer followed by the fragment size in bases (e.g., NBS9+em3_117). In all cases, loci shown in black are co-dominant; dominant markers in red originated in the S-4-1 parent and those in blue originated in S-4-4; the position of NIRPT is indicated in green.

The haploid genome of $N$. langsdorffii consists of nine chromosomes, and a complete molecular marker map would be expected to have a corresponding number of LGs. In the map presented here, the nine largest LGs (LG1 through LG9) consist of between 18 (LG9) and 42 (LG1) loci (53 and $101 \mathrm{cM}$, respectively) with a cumulative length of $937 \mathrm{cM}$. There were also three LGs of only four marker loci each (LG-A, LG-B, and LG-C; 11 AFLPs, and one SSR) that had a combined length of $125 \mathrm{cM}(11.8 \%$ of the total map distance). Twenty-four markers (7.5\%) did not show strong linkage to any LG, and they were excluded from the analysis. NIRPT is located in a distal region of LG3 $(111 \mathrm{cM})$, flanked by 4 AFLP loci and one SSR (GIS_A6) that together define a $\sim 10 \mathrm{cM}$ region of this linkage group.

\section{CLUSTER ANALYSIS IN N. LANGSDORFFII AND NICOTIANA SECTION ALATAE}

A distance matrix derived from the binary AFLP data generated with six primer pairs was clustered using the N-J algorithm. The resulting tree (Figure 2A) shows the phylogenetic relationships within the group of $14 \mathrm{~N}$. langsdorffii accessions, and between $\mathrm{N}$. langsdorffii and four other related species in section Alatae. Bootstrap support values based on 1000 iterations are $>50 \%$ for all nodes; only 1 (the S-4-4/S-4-6 pairing) is $<60 \%$, and 12 out of 16 are $>95 \%$. In this analysis, $N$. langsdorffii is monophyletic and is sister to $N$. forgetiana, although the 14 accessions of $N$. langsdorffii are distributed between two major clusters (A and B), both of which show some substructure. The $N$. langsdorffi $+N$. forgetiana cluster is sister to $N$. alata, another species with a haploid chromosomal complement of $n=9$. The N-J tree also shows that $N$. longiflora $(n=10)$ and $N$. bonariensis are not closely related to one another, nor are they closely related to the major cluster containing $N$. langsdorffi, $N$. forgetiana, and N. alata. Dominant HR-mediated resistance to $P$. tabacina appears to be expressed by species in both clusters of Nicotiana section Alatae.

The AFLP data matrix was also examined by PCoA, a multivariate ordination method used to visualize relationships within a data set. In PCoA, pairwise distances computed between individual variables are projected as coordinates upon a set of derived orthogonal axes, and similar cases group together. The distribution of the 18 Nicotiana accessions from Section Alatae is shown in Figure 2B. Eigenvalues for the first three PCO axes were 19.681, 14.502 , and 10.058 , respectively, representing $44.241 \%$ of the total variation. The major clusters from the N-J cluster analysis are retained, and PCoA shows the relationships between the different accessions more clearly than does the $\mathrm{N}$-J tree. The close similarity between S-4-1 and S-4-5 is readily apparent, as are the outlying positions of S-4-8 in cluster A and S-4-3 in cluster B-2. The only real difference between the two analyses of the AFLP data is that subclusters A-1 and A-2 appear not to be resolved in the PCoA plot of axes 1 and 2, although these two groups are well separated on axis 3 in a three-dimensional plot (not shown).

\section{DISCUSSION}

\section{LINKAGE MAPPING IN N. LANGSDORFFII}

Detection of linkage to molecular markers, and subsequent linkage mapping, are the prerequisites for map-based cloning of a candidate plant disease resistance gene. Because N. langsdorffii is genetically uncharacterized, we chose to use AFLPs to construct a basic linkage map framework onto which we would then map NIRPT and other classes of molecular markers such as SSRs, 
CAPS, and ISSRs. AFLP is a PCR-based technique that combines RFLP with specific amplification of small genomic DNA fragments (Vos et al., 1995). AFLPs have wide utility in plant genetics, particularly in the areas of linkage map construction, genetic diversity analyses, population studies, and cultivar identification (DNA fingerprinting). Microsatellites, or SSRs, are highly variable loci that are distributed widely throughout eukaryotic genomes (Tautz, 1989) and have proven to be informative genetic markers in plants (Phillips and Vasil, 2001; Varshney et al., 2005). SSRs are co-dominant and generally display a high level of polymorphism in outcrossing species (Morgante and Olivieri, 1993; Koreth et al., 1996). We also employed other types of polymorphic amplifiable molecular markers, such as SCAR (Albani et al., 2004), COSII (Wu et al., 2006), ISSR (Sankar and Moore, 2001), and TRAP (Hu and Vick, 2003) markers in construction of the first linkage map of the N. langsdorffii genome.
While our choice of mapping population structure may seem novel, it allowed us to collect allelic segregation data for several different types of molecular markers and integrate the data in a common format. We refer here to the set of progeny used in the mapping of NIRPT as a "modified backcross" population, but these plants are actually $\mathrm{F}_{1}$ hybrids between $N$. langsdorffii and $N$. forgetiana. What gives this population genetic utility is the fact that the female parent was a hybrid between two distinct genotypes of N. langsdorffii, S-4-1 and S-4-4. Like a standard backcross population, genetic linkage estimates were calculated from meiotic recombination that occurred in the S-4-1 $\times \mathrm{S}-4-4 \mathrm{~F}_{1}$ parent only. N. forgetiana is closely related to $N$. langsdorffii; the two species share the same number of chromosomes $(2 n=18)$, and are interfertile. In a genomic sense, however, $N$. forgetiana is distinct enough from $N$. langsdorffii such that we could readily identify fluorescent AFLP peaks unique to either of the two parental $N$.

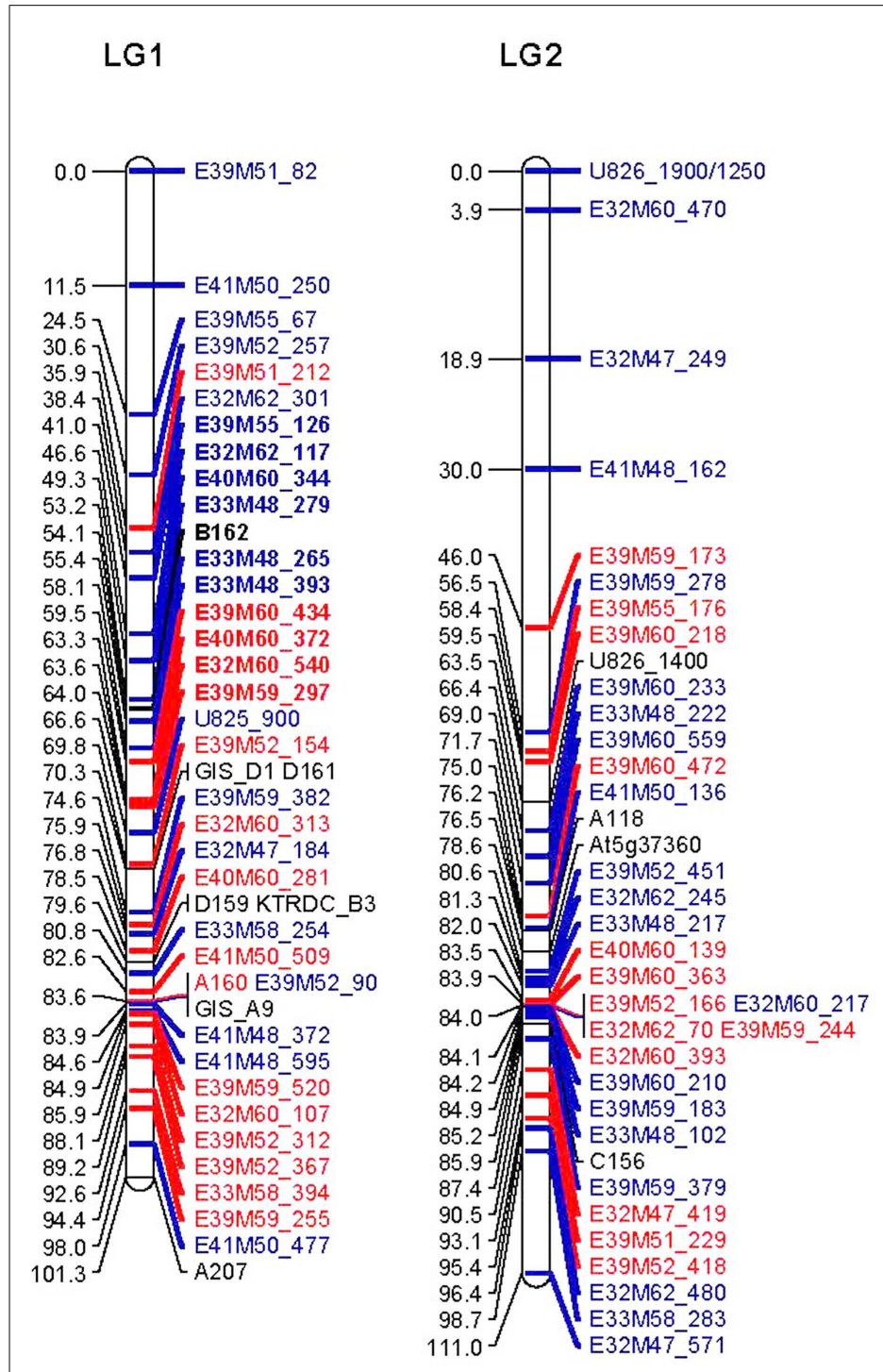

\section{LG3}

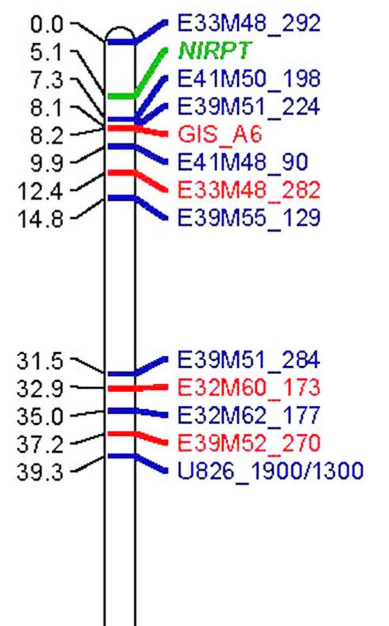

LG4

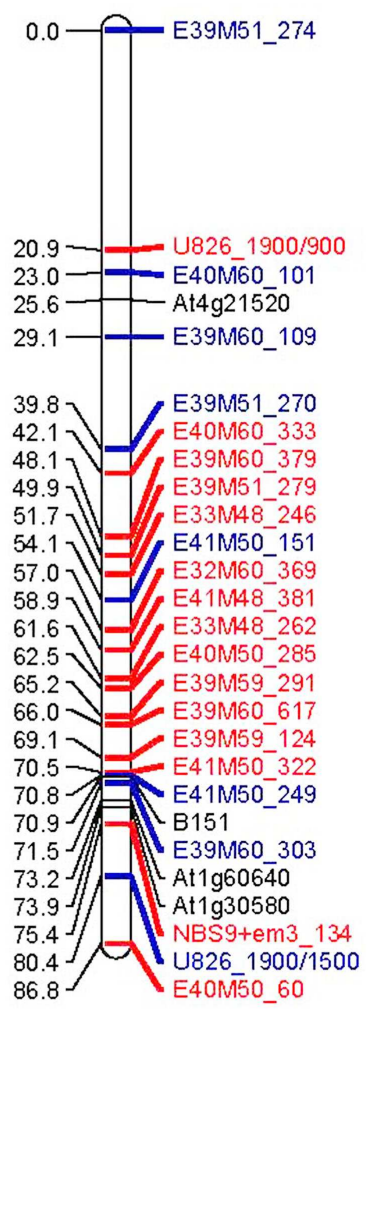

FIGURE 1 | Continued 


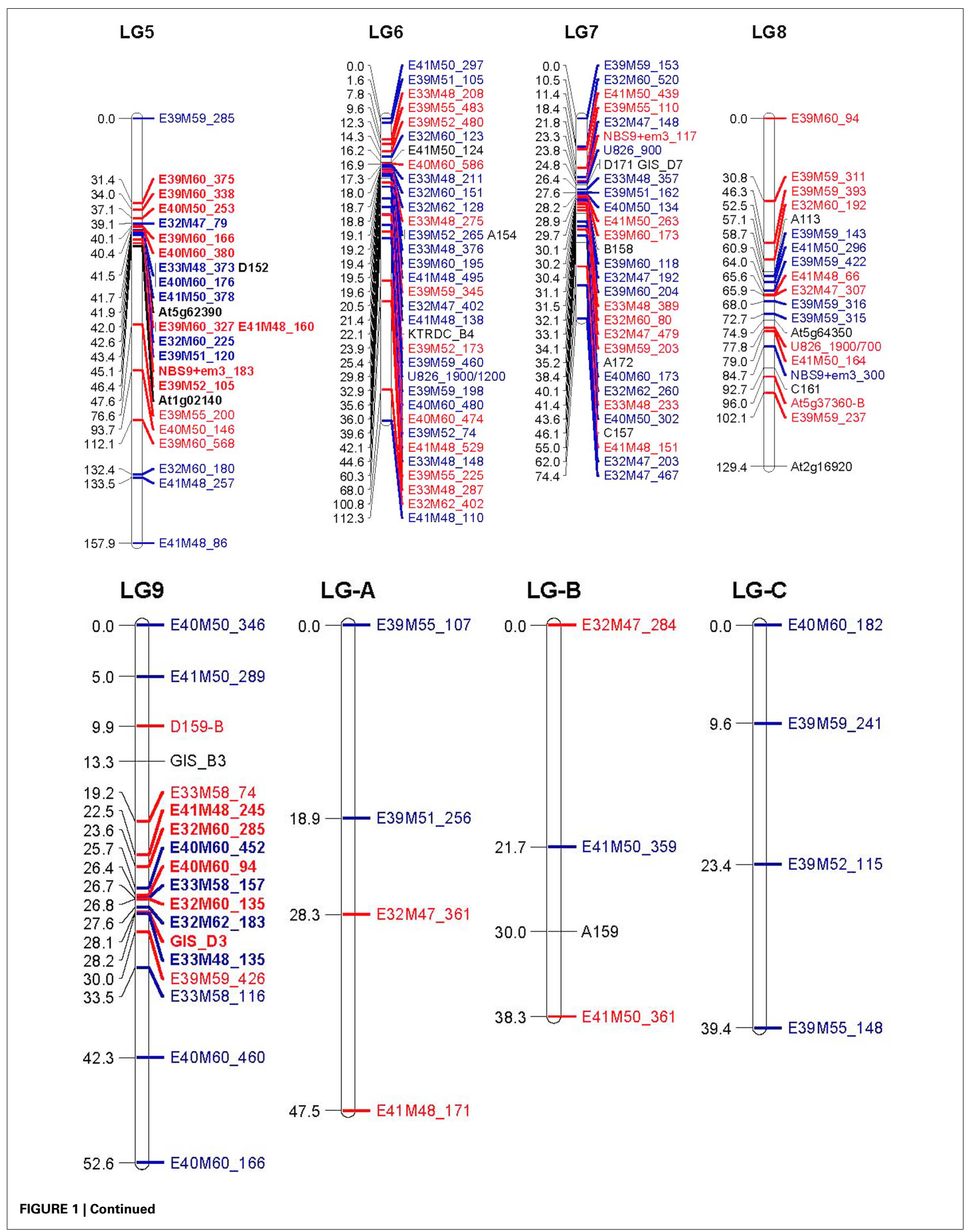




\author{
FIGURE 1 | Molecular marker linkage map of the Nicotiana \\ langsdorffii genome. The 12 linkage groups (LGs 1-9 plus LG-A, -B, and \\ $-C)$ together comprise a recombinational length of $1062 \mathrm{cM}$. The vast \\ majority of the markers were present in only one of the two parental \\ inbred lines used in the segregation studies. Loci indicated in red \\ originated in S-4-1 (susceptible to P. tabacina), while those in blue came \\ from S-4-4 (resistant to $P$. tabacina). Markers with alleles present in both \\ S-4-1 and S-4-4 are shown in black. The R-gene locus, NIRPT, is shown in \\ green. Locus names in the three segregation distortion regions (SDRs) on
}

LGs 1, 5, and 9 are shown in boldface. Locus nomenclature: AFLPs - primer combination followed by fragment size in bases (e.g., ExxMxx_123); SSRs - locus names begin with A, B, C, D, GIS, or KTRDC; COSII - AtXg followed by a five digit number; ISSR loci - U825 or U826 followed by the fragment in bases; ISSR/SCAR - cloned fragment size indicated as a four digit number, followed by the size of the scored fragment if different (e.g., U826_1900/700); TRAP loci-gene-specific primer+random primer followed by the fragment size in bases (e.g., NBS9+em3_117). langsdorffii accessions (S-4-1 and S-4-4) that were not present in N. forgetiana S-11-2. This approach allowed us to score AFLPs that originated from either S-4-1 or S-4-4 without having to be concerned with interfering peaks from the $N$. forgetiana parent. We used the same strategy to score allelic DNA fragments amplified with primer pairs for SSR, COSII, SCAR, and CAPS markers which, unlike AFLPs and TRAP markers, generally show co-dominant inheritance. The expected segregation ratios for all markers and the resistance gene NIRPT were 1:1 in this population.

We initially used BSA to identify AFLPs that were linked to NIRPT. BSA is a powerful method for identifying molecular markers that show association with a gene of interest or a specific region of the genome (Michelmore et al., 1991). By pooling DNA from individuals with the same phenotype, only the region of the genome surrounding a specific genetic locus is compared for the two parental alleles. BSA has been widely used in many crop species for detecting markers linked to single genes conferring disease resistance (Asnaghi et al., 2003; Hyten et al., 2009), and has recently been shown to have utility for mapping QTL for clubroot resistance in Brassica napus (Werner et al., 2008). Due to the dominant inheritance of NlRPT and the composition of the two susceptible bulks (S\#1 and S\#2), only markers linked in cis would be detected by BSA. All four of the AFLPs that showed association with NIRPT by BSA also showed genetic linkage to NlRPT on the map (Figure 1). We identified a fifth peak (E36M49_261) that showed association with the resistance gene, but because the primer combination E36M49 was used only in the BSA screening, it does not appear on the linkage map. Another 12 AFLPs were found that met most but not all of the screening criteria given above (i.e., absent in one $S$ bulk but present in the other, drastically reduced but not absent in the two $S$ bulks, etc.). Of these, only E41M50_198 was linked to NIRPT.

We identified 10 COSII markers, originally mapped in the tomato genome (Mueller et al., 2005; Wu et al., 2006), that were polymorphic between N. langsdorffii S-4-1 and S-4-4. Markers of this general class were included in an attempt to detect any macrosynteny that might exist between S. lycopersicum and $N$. langsdorffii. One of these COSII markers (At2g34560) did not show linkage to any of the other marker loci on the N. langsdorffii map. The other 9 primer pairs gave segregation data for 10 genetic loci - At5g37360 had two bands that segregated independently following digestion of the PCR products with DpnII. The ten COSII markers mapped to single loci on the N. langsdorffi linkage map, with three on LG4, three on LG8, two on LG5, and one each on LGs 2 and 3. The three COSII markers on LG4 (At1g30580, At1g60640, and At4g21520) all map to chromosome 2 in tomato. The marker locus order is similar between the two maps, although the recombination distances are quite different. A fourth marker, At2g34560, also from tomato chromosome 2 was polymorphic in our mapping population but was not included (see above). Of the three COSII markers mapped to LG8, two of them (At2g16920 and At5g64350) map to chromosome 1 in tomato. The third COSII marker on LG8 is At5g37360, which maps to a locus on tomato chromosome 4 . This discrepancy is probably explained by the fact that we mapped a secondary locus (designated "B") for this marker that was not detected in tomato, and therefore does not appear on the tomato linkage map. LG5 has two COSII marker loci, both of which map to chromosome 3 in tomato. Based on these highly conserved COSII markers, LGs 4, 5, and 8 in $N$. langsdorffi may correspond, at least in part, to tomato chromosomes 2, 3, and 1, respectively. This assessment is based on very limited data, and further mapping of characterized COSII markers on the $N$. langsdorffii genome will be needed to define the relationships between the 12 chromosomes of tomato and the 9 chromosomes of $N$. langsdorffii. Three of the COSII markers mapped in $N$. langsdorffii were also mapped in two other species of Nicotiana; Atlg30580, and At2g16920 were mapped in N. tomentosiformis, and At5g37360 was mapped in this species and also in $N$. acuminata (Wu et al., 2010). Because these three markers mapped to loci on three different chromosomes in N. tomentosiformis, their utility for interspecific comparative genomics is limited at present.

Segregation distortion (SD), defined as the statistically significant deviation of genotypic frequencies from Mendelian expectation (Lu et al., 2002), was observed for a subset of the marker loci. Twenty-nine of the most highly distorted $(p<0.01)$ loci were removed from the data set and the map was recalculated. All of these were AFLP markers, and it is possible that the observed distortion could be due to difficulties encountered in scoring the peaks, or to differential peak amplification from some progeny DNA during PCR. In the final version of the linkage map, 61 $(22.9 \%)$ of the marker loci exhibited SD $(p<0.05)$ and were distributed over all LGs except LGs 4, B, and C. We detected three segregation distortion regions (SDRs) on LGs 1,5 , and 9 that together comprised 38 loci covering $45 \mathrm{cM}$ (indicated in bold in Figure 1). The SDR on LG1 (11 loci and $23 \mathrm{cM}$ ) is skewed toward the S-4-4 (male) parent, while the SDRs on LG5 (18 loci, $16.2 \mathrm{cM}$ ) and LG11 ( 9 loci, $5.8 \mathrm{cM}$ ) both favor alleles from S-4-1 (the female parent). Overall, $62 \%$ of the distorted loci are located within SDRs. $\mathrm{SD}$ is a common feature of plant genetic linkage maps; it is frequent in progeny derived from interspecific crosses, and distortion tends to increase with increasing numbers of meioses in intraspecific crosses (Lu et al., 2002; Thoquet et al., 2002). The presence of SDRs can indicate that some genetic or physiological mechanism, such as gametophytic or zygotic selection, may be the underlying 


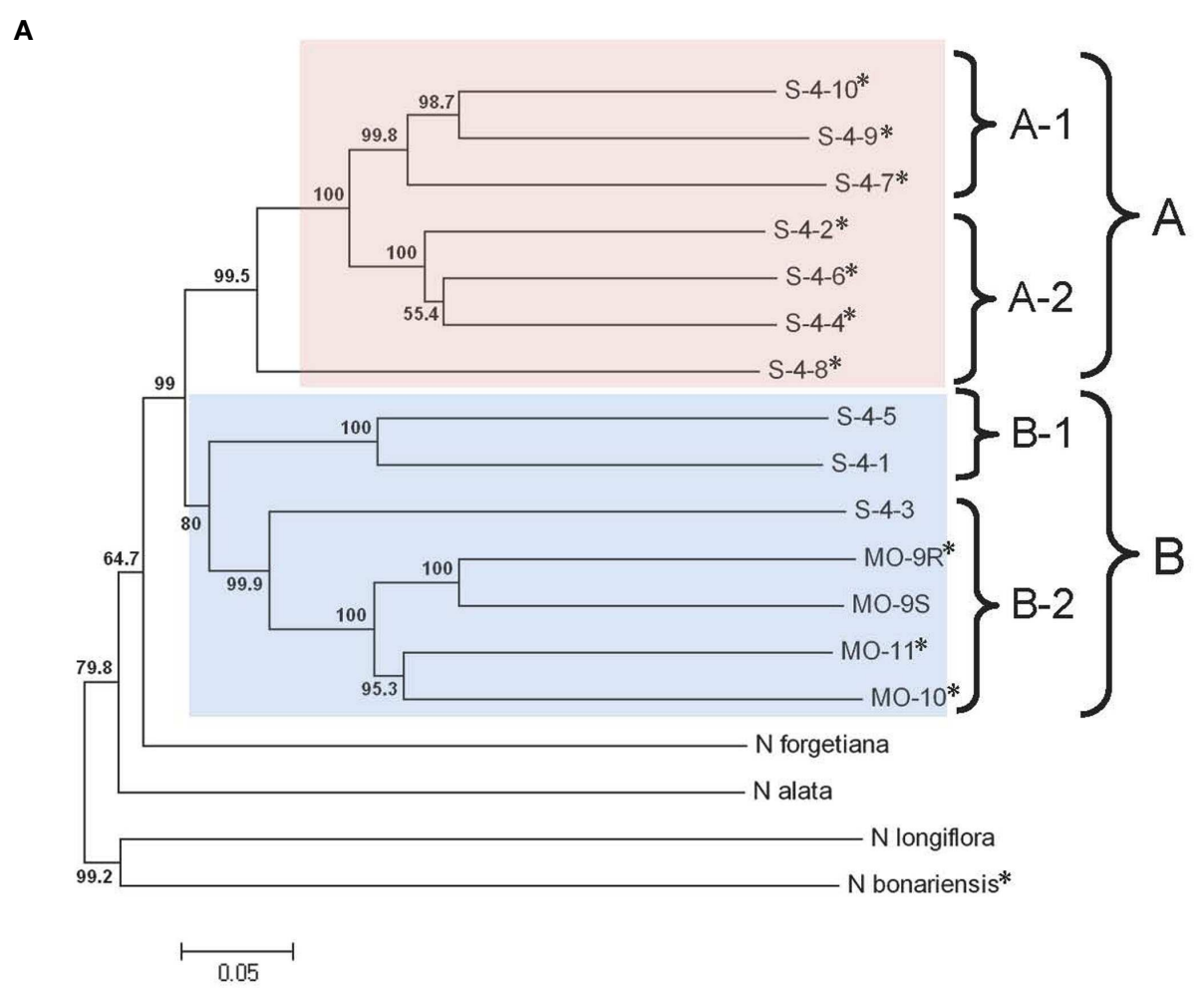

B Nicotiana PCoA

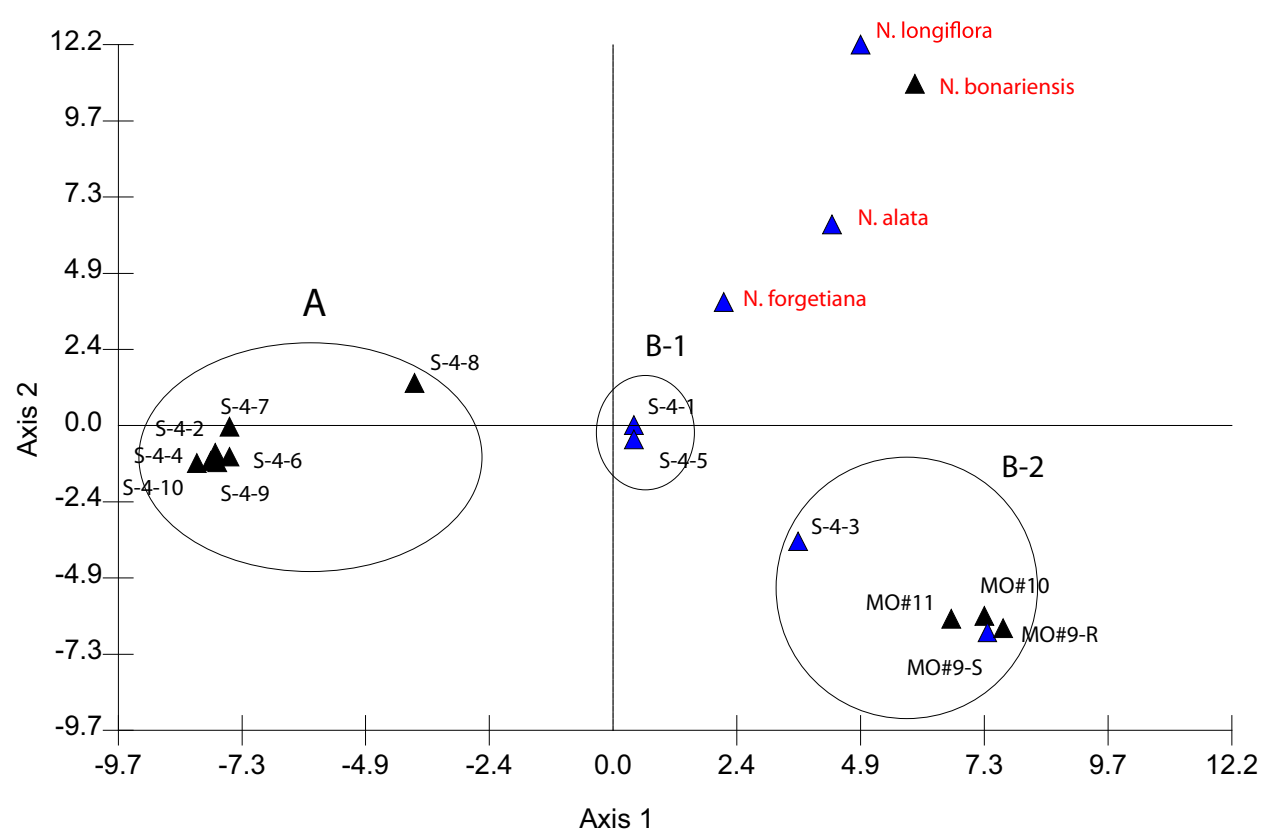

FIGURE 2 | (A) Neighbor-joining (N-J) tree showing the relationships between 14 accessions of $N$. langsdorffii and four other species in Nicotiana section Alatae. Bootstrap values (1000 iterations) are shown adjacent to the nodes. Clusters $A$ (pink) and $B$ (blue) define the two lineages of $N$. langsdorffii; subclusters A-1, A-2, B-1, and B-2 are indicated by brackets. Accessions with an asterisk (*) displayed an incompatible interaction (HR) when infected by $P$. tabacina and are therefore resistant to this pathogen. (B) Principal coordinates analysis (PCOA) of the AFLP data for Nicotiana section Alatae. The first two orthogonal axes explain $34.183 \%$ of the total variation. Clusters A, B-1, and B-2 correspond to the clusters present in the $\mathrm{N}-\mathrm{J}$ tree. All accessions of $\mathrm{N}$. langsdorffii are labeled in black, while the other species in sect. Alatae are shown in red. Accessions that are either susceptible or resistant to $P$. tabacina infection are indicated by blue and black triangles, respectively. 
cause of the observed SD. In N. langsdorffii, we can only speculate as to the existence of the three SDRs. Both of the original parents of the mapping population, S-4-1 and S-4-4, are highly inbred, and we have observed that S-4-1 has much lower seed set, and both poorer and delayed germination when compared to S-4-4 (unpublished). Deleterious alleles originating from S-4-1 for one or more of these traits could account for the largest SDR, which is on LG1 and is strongly skewed toward alleles from S-4-4.

The linkage map and molecular markers developed for the $N$. langsdorffii genome could be useful tools for map-based cloning of NIRPT. The NIRPT locus on LG3 is flanked most closely by three cis-linked AFLP markers that originated in S-4-4, the source of this resistance gene. To make these markers useful for isolating NIRPT, AFLP fragments E33M48_292, E41M50_198, and E39M51_224 would need to be cloned and sequenced to convert them into SCAR markers. At present, E41M50_198 is the closest locus to NIRPT, and it is $\sim 2.3 \mathrm{cM}$ distant. A much larger $\mathrm{F}_{2}$ mapping population and focused screening of the COSII marker collection would be needed to identify flanking marker loci that are tightly linked $(<1 \mathrm{cM})$ to NIRPT. Additional genomic resources, such as an extensive EST collection and draft genome sequence, would be very useful for isolating important genes from $N$. langsdorffii. Like many species of Nicotiana, N. langsdorffii (a diploid) has a large genome, in this case $\sim 4300 \mathrm{Mbp}$ (Narayan, 1987), which is $\sim 15 \%$ smaller than that reported for the allopolyploid N. tabacum (Leitch et al., 2008).

\section{GENETIC RELATIONSHIPS WITHIN NICOTIANA SECTION ALATAE}

We also used AFLP marker data in a phenetic clustering study to examine the relationships between $14 \mathrm{~N}$. langsdorffii accessions and four other closely related species in Nicotiana section Alatae, 11 of which expressed dominant resistance to P. tabacina. Previous studies in plants have demonstrated that AFLPs are particularly informative in closely related taxa, where potential errors in genetic distance estimates due to fragment homoplasy are minimized (Crawford and Mort, 2004; Parks et al., 2006; Krichen et al., 2008). In their study of relationships within Echinacea, Kim et al. (2004) used an automated DNA sequencing instrument for fluorescent AFLP detection, demonstrating that individual fragments are amplified very reliably in this adaptation of an already robust technology. We used the same instrument (Beckman Coulter CEQ8000) in this study, and analysis of our data showed conclusively that AFLPs are highly informative in N. langsdorffii and could be used for genetic mapping and to infer genetic relationships within section Alatae. The N-J tree computed from the AFLP data clearly resolved the 14 accessions of $N$. langsdorffii into two well-defined clusters (A and B), with $N$. forgetiana as the sister species to N. langsdorffii (Figure 2A). The conclusions drawn from the N-J analysis are fully supported by PCoA of the same AFLP data set. In PCoA, the relationships between the plant accessions can be displayed spatially in either 2- or 3-dimensional plots. In our analysis, the relative positions of $N$. langsdorffi accessions S4-3 and S-4-8 can be visualized more clearly than in the N-J tree, as can the relationships between the $14 \mathrm{~N}$. langsdorffii accessions and the other four species of Nicotiana in section Alatae (Figure 2B).

Previous experience with AFLP data from wild and cultivated Sinningia speciosa (the florist's gloxinia of horticulture) showed that clustering methods (N-J, UPGMA, and PCoA) applied to binary AFLP data grouped plant accessions by geographical origins, where known, and made it possible to assign unknown accessions to regions of southeastern Brazil based on cluster assignments (D. Zaitlin, unpublished). In the purple coneflower (Echinacea angustifolia), a N-J tree derived from AFLP data for 10 US populations along a north-south climatic gradient also displayed a very strong geographical association for all clades (Still et al., 2005). The only $N$. langsdorffii accessions for which we have collection data are those designated MO-9 (R and S), MO-10, and MO-11, which are from the adjacent towns of Papanduva (MO-9) and Major Vieira (MO-10 and MO-11) in the southern Brazilian state of Santa Catarina. These four accessions grouped together in cluster B along with S-4-1, S-4-3, and S-4-5, the three accessions that form compatible interactions with P. tabacina. According to Goodspeed (1954), N. langsdorffii occupies a large area in South America, extending from the Brazilian states of Rio de Janeiro and southern Minas Gerais in the east, southwest through São Paulo, Paraná and Santa Catarina into eastern Paraguay and northeastern Argentina. Thus, for N. langsdorffii, the two major clusters could very well represent distinct lineages that originated from different regions within the geographical range of this species.

Our present knowledge of dominant HR-mediated resistance to P. tabacina indicates that this specific reaction is limited to species in Nicotiana section Alatae. We previously identified this form of host-pathogen incompatibility in $\sim 70 \%$ of the $N$. langsdorffii accessions that we tested (Zhang and Zaitlin, 2008). Controlled inoculations of the available accessions of $N$. forgetiana $(n=2)$, $N$. alata (4), N. longiflora (5), and N. plumbaginifolia (2) revealed that these species, like $N$. tabacum, are fully permissive hosts for the blue mold pathogen. Plants of a single accession of $N$. bonariensis expressed a necrotic lesion reaction when inoculated with asexual sporangia of $P$. tabacina. This reaction was indistinguishable from those observed on resistant accessions of $N$. langsdorffi in terms of appearance, time of onset, and the fact that it completely prevented the pathogen from colonizing the inoculated leaves (not shown). If this resistance is due to expression of an orthologous gene present in $N$. bonariensis, the $\mathrm{N}-\mathrm{J}$ tree indicates that resistance could have evolved in the common ancestor of these two species. Of course, further genetic studies and cloning of the gene will be necessary to determine if it is orthologous to NIRPT from N. langsdorffii.

\section{CROSS-SPECIES UTILITY OF $\boldsymbol{N}$. LANGSDORFFII SSR MARKERS}

We were able to design acceptable primer pairs flanking SSR motifs for 98 of the genomic clones (out of $>300$ sequenced). Of these, 30 gave length polymorphisms that distinguished the parents of our N. langsdorffii mapping population (S-4-1 and S-4-4) from one another, and 25 of them map to loci on the molecular linkage map (Figure 1). Our initial screening panel of genomic DNA samples also included two accessions each of $N$. alata and $N$. longiflora, $n=9$ and $n=10$ species in section Alatae, respectively. Approximately $60 \%$ of the SSR primer pairs directed amplification of discreet genomic fragments from these two species. Thirteen detected polymorphism in N. alata, and 20 in N. longiflora, indicating their potential utility as genetic markers in species related to $N$. langsdorffii. We also screened 20 of these primer pairs, eight of which (GIS_A4, GIS_B3, GIS_D1, A113,A118,A159, B162, and 
C156) were used for mapping in N. langsdorffi, against six accessions of the Australian species $N$. benthamiana (section Suaveolentes). Unexpectedly, all gave discreet amplification products from $N$. benthamiana genomic DNA. This result, while not definitive, supports the genomic hybridization experiments of Chase et al. (2003), which show that an ancestral species from section Alatae was one of the progenitors of sect. Suaveolentes (all are of polyploid origin), a concept originally proposed by Goodspeed (1954).

\section{CONCLUSION}

The research presented herein shows conclusively that molecular markers are useful for constructing a linkage map of the $N$. langsdorffii genome and for detecting associations between marker loci and known R-genes. BSA, using pools of $\mathrm{F}_{2}$ plants that were susceptible to $P$. tabacina infection, was an effective strategy for identifying AFLP markers linked to the resistance gene NIRPT. We also showed that the structure of the mapping population (a "modified backcross") allowed all markers, even those with null alleles, to be scored in the same way, making calculation of the linkage map very straightforward. Several AFLPs and one SSR marker locus showed linkage to NIRPT at the distal end of LG3. For map-based cloning of this gene, at least two of the flanking AFLP markers (E33M48_292 and E41M50_198) would need to be converted into more user-friendly (i.e., SCAR) markers. As is common in genetic linkage mapping, some of the marker loci showed evidence of SD. The SD observed in this N. langsdorffii mapping population was largely confined to three SDRs on LGs 1, 5, and 9, accounting for 38 marker loci and $45 \mathrm{cM}(4.2 \%$ of the total map length). In the largest SDR ( $23 \mathrm{cM}$ on LG1), marker alleles are strongly skewed toward the S-4-4 parent, indicative of a possible physiological effect.

Our study also demonstrated that AFLP-based phenetic analyses can be used to elucidate relationships within N. langsdorffii, and between this taxon and related species in Nicotiana section Alatae. PCoA (Figure 2B) strongly indicated that there are two or three

\section{REFERENCES}

Albani, M. C., Battery, N. H., and Wilkinson, M. J. (2004). The development of ISSR-derived SCAR markers around the seasonal flowering locus (SFL) in Fragaria vesca. Theor. Appl. Genet. 109, 571-579.

Asnaghi, C., Roques, D., Ruffel, S., Kaye, C., Hoarau, J.-Y., Télismart, H., Girard, J. C., Raboin, L. M., Risterucci, A. M., Grivet, L., and D'Hont, A. (2003). Targeted mapping of a sugarcane rust resistance gene (Brul) using bulked segregant analysis and AFLP markers. Theor. Appl. Genet. 108, 759-764.

Bai, D., Reeleder, R., and Brandle, J. E. (1995). Identification of two RAPD markers tightly linked with the Nicotiana debneyi gene for resistance to black root rot of tobacco. Theor. Appl. Genet. 91, 1184-1189.

Bindler, G., Plieske, J., Bakaher, N., Gunduz, I., Ivanov, N., Van der

genetic lineages represented in the 14 accessions of $N$. langsdorffi included in this study, which could be related to their geographical origins. HR-mediated resistance to $P$. tabacina is present in both major clusters (A and B-2), and also in the related species $N$. bonariensis.

A recent AFLP-based analysis of $N$. benthamiana (Goodin et al., 2008) indicated that most of the accessions used in research have very limited genetic diversity. However, one accession (USDA PI\#555684) included in the distance-based diversity study is a much larger plant that is morphologically close to the type collection that proved to be distinct from all of the research accessions (see Figure 3 of Goodin et al., 2008). Our limited screening of the N. langsdorffii SSR marker primers showed that 6 out of 20 detected polymorphism within the group of $N$. benthamiana accessions, and in all cases PI\#555684 was different from the five research accessions, which were identical (data not shown). Thus, many of the SSR markers developed for the N. langsdorffii genome are of potential use for genetic studies in N. benthamiana and its close relatives in section Suaveolentes.

\section{AUTHORS CONTRIBUTIONS}

Shouan Zhang participated in the design of the mapping strategy, generated much of the AFLP and molecular marker data, and drafted and proofread the manuscript. Muqiang Gao assisted with data generation and collection, and helped with the linkage mapping. David Zaitlin directed the project, developed the molecular markers and mapping population, generated allelic marker data, and wrote the manuscript.

\section{ACKNOWLEDGMENTS}

The authors thank the Kentucky Tobacco Research Board (KTRB) for research funding, James T. Hall for assistance in the laboratory, Bonnie Kinney for maintaining plants in the greenhouse, and Dr. $\mathrm{H}$. Zhu for providing the mapping software. We are also indebted to the staff of the UK-AGTC, under the direction of C. L. Schardl, for their excellent assistance with DNA sequencing.

WRR4, a broad-spectrum TIR-NBLRR gene from Arabidopsis thaliana that confers white rust resistance in transgenic oilseed brassica crops. Mol. Plant Pathol. 11, 283-291.

Chase, M. W., Knapp, S., Cox, A. V., Clarkson, J. J., Butsko, Y., Joseph, J., Savolainen, V., and Parokonny, A. S. (2003). Molecular systematics, GISH and the origin of hybrid taxa in Nicotiana (Solanaceae). Ann. Bot.92, 107-127.

Clayton, E. E. (1945). Resistance of tobacco to blue mold (Peronospora tabacina). J. Agric. Res. 70, 79-87.

Clayton, E. E. (1967). The transfer of blue mold resistance to tobacco from Nicotiana debneyi. Part III. Development of a blue mold resistant cigar wrapper variety. Tobacco Sci. 11, 107-110.

Clayton, E. E. (1968). The transfer of blue mold resistance to tobacco from Nicotiana debneyi. Part IV. Breeding programs 1957-1967. Tobacco Sci. 12, 112-124.

Cooke, D. E. L., Williams, N. A., Williamson, B., and Duncan, J. M. (2002). "An ITS-based phylogenetic analysis of the relationships between Peronospora and Phytophthora," in Advances in Downy Mildew Research, eds Spencer-Phillips, P. T. N., Gisi, U., and Lebeda, A. (Dordrecht: Kluwer Academic Publishers), 161-166.

Crawford, D. J., and Mort, M. E. (2004). Single-locus molecular markers for inferring relationships at lower taxonomic levels: observations and comments. Taxon 53, 631-635.

Dick, M. W. (2002). "Towards an understanding of the evolution of the downy mildews," in Advances in Downy Mildew Research, eds Spencer-Phillips, P. T. N., Gisi, U., and Lebeda, A. (Dordrecht: Kluwer Academic Publishers), 1-57. 
Dinesh-Kumar, S. P., Whitham, S., Choi, D., Hehl, R., Corr, C., and Baker, B. (1995). Transposon tagging of tobacco mosaic virus resistance gene $\mathrm{N}$ : its possible role in the TMV-Nmediated signal transduction pathway. Proc. Natl. Acad. Sci. U.S.A. 92, 4175-4180.

Fulton, T., Van der Hoeven, R., Eannetta, N. T., and Tanksley, S. D. (2002). Identification, analysis and utilization of conserved ortholog set markers for comparative genomics in higher plants. Plant Cell 14, 1457-1467.

Gisi, U. (2002). "Chemical control of downy mildews," in Advances in Downy Mildew Research, eds Spencer-Phillips, P. T. N., Gisi, U., and Lebeda, A. (Dordrecht: Kluwer Academic Publishers), 119-159.

Göker, M., Voglmayr, H., Riethmüller, A., and Oberwinkler, F. (2007). How do obligate parasites evolve? A multigene phylogenetic analysis of downy mildews. Fungal Genet. Biol. 44, 105-122.

Goodin, M. M., Zaitlin, D., Naidu, R. A., and Lommel, S. A. (2008). Nicotiana benthamiana: its history and future as a model for plant-pathogen interactions. Mol. Plant Microbe Interact. 21, 1015-1026.

Goodspeed, T. H. (1954). The genus Nicotiana: origins, relationships and evolution of its species in the light of their distribution, morphology and cytogenetics. Chron. Bot. 16, 49-57.

Hein, I., Gilroy, E. M., Armstrong, M. R., and Birch, P. R. J. (2009). The zigzag-zig in oomycete-plant interactions. Mol. Plant Pathol. 10, 547-562.

Holmes, F. O. (1938). Inheritance of resistance to tobacco-mosaic disease in tobacco. Phytopathology 28, 553-561.

Hu, J., and Vick, B. A. (2003). Target region amplification polymorphism, a novel marker technique for plant genotyping. Plant Mol. Biol. Rep. 21, 289-294.

Hyten, D. L., Smith, J. R., Frederick, R. D., Tucker, M. L., Song, Q., and Cregan, P. B. (2009). Bulked segregant analysis using the GoldenGate assay to locate the Rpp3 locus that confers resistance to soybean rust in soybean. Crop Sci. 49, 265-271.

Jeuken, M., van Wijk, R., Peleman, J., and Lindhout, P. (2001). An integrated interspecific AFLP map of lettuce ( Lactuca) based on two L. sativa $\mathrm{X}$ L. saligna F2 populations. Theor. Appl. Genet. 103, 638-647.

Johnson, E. S., Wolff, M. F., and Wernsman, E. A. (2002a). Origin of the black shank resistance gene, $P h$, in tobacco cultivar Coker 371-Gold. Plant Dis. 86, 1080-1084.

Johnson, E. S., Wolff, M. F., and Wernsman, E. A. (2002b). Marker-assisted selection for resistance to black shank disease in tobacco. Plant Dis. 86, 1303-1309.

Johnson, G. F. (1935). The early history of copper fungicides. Agric. Hist. 9, 67-79.

Julio, E., Denoyes-Rothan, B., Verrier, J.-L., and Dorlhac de Borne, F. (2006a). Detection of QTLs linked to leaf and smoke properties in Nicotiana tabacum based on a study of 114 recombinant inbred lines. Mol. Breed. 18, 69-91.

Julio, E., Verrier, J.-L., and Dorlhac de Borne, F. (2006b). Development of SCAR markers linked to three disease resistances based on AFLP within Nicotiana tabacum L. Theor. Appl. Genet. 112, 335-346.

Kamoun, S., Huitema, E., and Vleeshouwers, V. G. A. A. (1999). Resistance to oomycetes: a general role for the hypersensitive response? Trends Plant Sci. 4, 196-200.

Kenward, K. D., Bai, D., Ban, M. R., and Brandle, J. E. (1999). Isolation and characterization of Tnd-1, a retrotransposon marker linked to blank root rot resistance in tobacco. Theor. Appl. Genet. 98, 387-395.

Kim, D.-H., Heber, D., and Still, D. W. (2004). Genetic diversity of Echinacea species based upon amplified fragment length polymorphism markers. Genome 47, 102-111.

Knapp, S., Chase, M. W., and Clarkson, J. J. (2004). Nomenclatural changes and a new sectional classification in Nicotiana (Solanaceae). Taxon 53, 73-82.

Konieczny, A., and Ausubel, F. M. (1993). A procedure for mapping Arabidopsis mutations using co-dominant ecotype-specific PCRbased markers. Plant J. 4, 403-410.

Koreth, J., O'Leary, J. J., and McGee, J. O. (1996). Microsatellites and PCR genome analysis. J. Pathol. 178, 239-248.

Krichen, L., Martins, J. M. S., Lambert, P., Daaloul, A., Trifi-Farah, N., Marrakchi, M., and Audergon, J.-M. (2008). Using AFLP markers for the analysis of the genetic diversity of apricot cultivars in Tunisia. J. Am. Soc. Hortic. Sci. 133, 204-212.

Lebeda, A., Sedlářová, M., Petřivalský, M., and Prokopová, J. (2008). Diversity of defence mechanisms in plantoomycete interactions: a case study of Lactuca spp. and Bremia lactucae. Eur. J. Plant Pathol. 122, 71-89.

Lee, C. B., Page, L. E., McClure, B. A., and Holtsford, T. P. (2008)
Post-pollination barriers in Nicotiana section Alatae. Sex. Plant Reprod. 21, 183-195.

Leitch, I. J., Hanson, L., Lim, K. Y., Kovarik, A., Chase, M. W., Clarkson, J. J., and Leitch, A. R. (2008). The ups and downs of genome size evolution in polyploid species of Nicotiana (Solanaceae). Ann. Bot. 101, 805-814.

Lewis, R. S. (2005). Transfer of resistance to potato virus Y (PVY) from Nicotiana africana to Nicotiana tabacum: possible influence of tissue culture on the rate of introgression. Theor. Appl. Genet. 110, 678-687.

Li, G., and Quiros, C. G. (2001). Sequence-related amplified polymorphism (SRAP), a new marker system based on a simple PCR reaction: its application to mapping and gene tagging in Brassica. Theor. Appl. Genet. 103, 455-461.

Lin, T. Y., Lao, Y. Y., Lin, S., Lin, R. F. Chen, C. M., Huang, C. H., Wang, C. K., Lin, Y. Z., and Chen, C. C. (2001). A genetic linkage map of Nicotiana plumbaginifolia/Nicotiana longiflora based on RFLP and RAPD markers. Theor. Appl. Genet. 103, 905-911.

Lu, H., Romero-Severson, J., and Bernard, R. (2002). Chromosomal regions associated with segregation distortion in maize. Theor. Appl. Genet. 105, 622-628.

Main, C. E. (1991). "Blue mold," in Compendium of Tobacco Diseases, eds Shew, H. D., and Lucas, G. B. (St. Paul, MN: American Phytopathological Society), 5-9.

Martin, G. B., Bogdanove, A. J., and Sessa, G. (2003). Understanding the functions of plant disease resistance proteins. Annu. Rev. Plant Biol. 54, 23-61.

Mauch-Mani, B. (2002). "Host resistance to downy mildew diseases," in Advances in Downy Mildew Research, eds Spencer-Phillips, P. T. N., Gisi, U., and Lebeda, A. (Dordrecht: Kluwer Academic Publishers), 59-83.

Michelmore, R. W., Paran, I., and Kesseli, R. V. (1991). Identification of markers linked to disease-resistance genes by bulked segregant analysis: a rapid method to detect markers in specific genomic regions by using segregating populations. Proc. Natl. Acad. Sci. U.S.A. 88, 9828-9832.

Milla, S. R., Levin, J. S., Lewis, R. S., and Rufty, R. C. (2005). RAPD and SCAR markers linked to an introgressed gene conditioning resistance to Peronospora tabacina D.B. Adam in tobacco. Crop Sci. 45, 2346-2354.

Moon, H., and Nicholson, J. S. (2007). AFLP and SCAR markers linked to tomato spotted wilt virus resistance in tobacco. Crop Sci. 47, 1887-1894.

Morgante, M., and Olivieri, A. M. (1993). PCR-amplified microsatellites as markers in plant genetics. Plant J. 3, 175-182.

Mueller, L. A., Solow, T. H., Taylor, N., Skwarecki, B., Buels, R., Binns, J., Lin, C., Wright, M. H., Ahrens, R., Wang, Y., Herbst, E. V., Keyder, E. R., Menda, N., Zamir, D., and Tanksley, S. D. (2005). The SOL genomics network. A comparative resource for Solanaceae biology and beyond. Plant Physiol. 138, 1310-1317.

Narayan, R. K. J. (1987). Nuclear DNA changes, genome differentiation and evolution in Nicotiana (Solanaceae). Plant Syst. Evol. 157, 161-180.

Nishi, T., Tajima, T., Noguchi, S., Ajisaka, H., and Negishi, H. (2003). Identification of DNA markers linked to bacterial wilt resistance. Theor. Appl. Genet. 106, 765-770.

Park, T.-H., Vleeshouwers, V. G. A. A., Jacobsen, E., Van Der Vossen, E., and Visser, R. G. F. (2009). Molecular breeding for resistance to Phytophthora infestans (Mont.) de Bary in potato (Solanum tuberosum L.): a perspective of cisgenesis. Plant Breed. 128, 109-117.

Parks, E. J., Moyer, J. W., and Lyerly, J. H. (2006). Identification of fluorescent AFLP and SSR markers for differentiation and analysis of New Guinea impatiens. J. Am. Soc. Hortic. Sci. 131, 622-631.

Petersen, A. B., and Rosendahl, S. (2000). Phylogeny of the Peronosporomycetes (Oomycota) based on partial sequences of the large ribosomal subunit (LSU rDNA). Mycol. Res. 104, 1295-1303.

Phillips, R. L., and Vasil, I. K. (eds). (2001). DNA-Based Markers in Plants. Dordrecht: Kluwer Academic Publishers.

Ren, N., and Timko, M. P. (2001). AFLP analysis of genetic polymorphism and evolutionary relationships among cultivated and wild Nicotiana species. Genome 44, 559-571.

Ristaino, J. B. (2002). Tracking historic migrations of the Irish potato famine pathogen, Phytophthora infestans. Microbes Infect. 4, 1369-1377.

Rohlf, F. J. (2007). NTSYSpc: Numerical Taxonomy and Multivariate Analysis System. Exeter Software, Ver. 2.20. Setauket, NJ: Exeter Publishing Ltd.

Rufty, R. C., Wernsman, E. A., Main, C. E., and Gooding, G. V. Jr. (1990). Registration of NC-BMR-42 and NC-BMR-90 germplasm lines of tobacco. Crop Sci. 30, 241-242. 
Saitou, N., and Nei, M. (1987). The neighbor-joining method: a new method for reconstructing trees. Mol. Biol. Evol. 4, 406-425.

Sankar, A. A., and Moore, G. A. (2001). Evaluation of inter-simple sequence repeat analysis for mapping in Citrus and extension of the genetic linkage map. Theor. Appl. Genet. 102, 206-214.

Slusarenko, A. J., and Schlaich, N. L. (2003). Downy mildew of Arabidopsis thaliana caused by Hyaloperonospora parasitica (formerly Peronospora parasitica). Mol. Plant Pathol. 4, 159-170.

Still, D. W., Kim, D.-H., and Aoyama, N. (2005). Genetic variation in Echinacea angustifolia along a climatic gradient. Ann. Bot. 96, 467-477.

Tautz, D. (1989). Hypervariability of simple sequences as a general source for polymorphic DNA. Nucleic Acids Res. 17, 6463-6471.

Thoquet, P., Ghérardi, M., Journet, E.P., Kereszt, A., Ané, J.-M., Prosperi, J.-M., and Huguet, T. (2002). The molecular linkage map of the model legume Medicago truncatula: an essential tool for comparative legume genomics and the isolation of agronomically important genes. BMC Plant Biol. 2, 1. doi:10.1186/1471-2229-2-1

Tyler, B. M., Tripathy, S., Zhang, X., Dehal, P., Jiang, R. H., Aerts, A., Arredondo, F. D., Baxter, L., Bensasson, D., Beynon, J. L., Chapman, J., Damasceno, C. M., Dorrance, A. E., Dou, D., Dickerman, A. W., Dubchak, I. L., Garbelotto, M., Gijzen, M., Gordon, S. G., Govers, F., Grunwald, N. J., Huang, W., Ivors, K. L., Jones, R. W., Kamoun, S., Krampis, K., Lamour, K. H., Lee, M. K., McDonald, W. H., Medina, M., Meijer, H. J., Nordberg, E. K., MacLean, D. J., Ospina-Giraldo, M. D., Morris, P. F., Phuntumart, V., Putnam, N. H., Rash, S., Rose, J. K., Sakihama, Y., Salamov, A. A., Savidor, A., Scheuring, C. F., Smith, B. M., Sobral,
B. W., Terry, A., Torto-Alalibo, T. A., Win, J., Xu, Z., Zhang, H., Grigoriev, I. V., Rokhsar, D. S., and Boore, J. L. (2006). Phytophthora genome sequences uncover evolutionary origins and mechanisms of pathogenesis. Science 313, 1261-1266.

Van Der Vossen, E., Sikkema, A., Hekkert, B. L., Gros, J., Stevens, P., Muskens, M., Wouters, D., Pereira, A., Stiekema, W., and Allefs, S. (2003). An ancient R gene from the wild potato species Solanum bulbocastanum confers broad-spectrum resistance to Phytophthora infestans in cultivated potato and tomato. Plant J. 36, 867-882.

Van Ooijen, J. W., and Voorrips, R. E. (2001). JoinMap Version 3.0: Software for the Calculation of Genetic Linkage Maps. Wageningen: Plant Research International.

Varshney, R. K., Graner, A., and Sorrells, M. E. (2005). Genic microsatellite markers in plants: features and applications. Trends Biotechnol. 23, 48-55.

Vleeshouwers, V. G. A. A., van Dooijeweert, W., Govers, F., Kamoun, S., and Colon, L. T. (2000). The hypersensitive response is associated with host and nonhost resistance to Phytophthora infestans. Planta 210, 853-864.

Voglmayr, H. (2003). Phylogenetic relationships of Peronospora and related genera based on nuclear ribosomal ITS sequences. Mycol. Res. 107, 1132-1142.

Voorrips, R. E. (2002). MapChart: software for the graphical presentation of linkage maps and QTLs. J. Hered. 93, 77-78.

Vos, P., Hogers, R., Bleeker, M., Reijans, M., van de Lee, T., Hornes, M., Frijters, A., Pot, J., Peleman, J., Kuiper, M., and Zabeau, M. (1995). AFLP: a new technique for DNA fingerprinting. Nucleic Acids Res. 23, 4407-4414.

Wang, M., Van den Berg, R., Van der Linden, G., and Vosman, G. (2008).
The utility of NBS profiling for plant systematics: a first study in tuber-bearing Solanum species. Plant Syst. Evol. 276, 137-148.

Werner, S., Diederichsen, E., Frauen, M., Schondelmaier, J., and Jung, C. (2008). Genetic mapping of clubroot resistance genes in oilseed rape. Theor. Appl. Genet. 116, 363-372.

Wieckhorst, S., Bachlava, E., Dußle, C. M., Tang, S., Gao, W., Saski, C. Knapp, S. J., Schön, C.-C., Hahn, V., Bauer, E. (2010). Fine mapping of the sunflower resistance locus $P l_{A R G}$ introduced from the wild species Helianthus argophyllus. Theor. Appl. Genet. 121, 1633-1644.

Wiglesworth, M. D., Reuveni, M., Nesmith, W. C., Siegel, M. R., Kuc, J., and Juarez, J. (1988). Resistance of Peronospora tabacina to metalaxyl in Texas and Mexico. Plant Dis. 72, 964-967.

Williams, J. G. K., Kubelik, A. R., Livak, K. J., Rafalski, J. A., and Tingey, S. V. (1990). DNA polymorphisms amplified by arbitrary primers are useful as genetic markers. Nucleic Acids Res. 18, 6531-6535.

Wolf, F. A. (1947). Tobacco downy mildew, endemic to Texas and Mexico. Phytopathology 37, 721-729.

Wu, F., Eannetta, N. T., Xu, Y., Plieske, J., Ganal, M., Pozzi, C., Bakaher, N., and Tanksley, S. D. (2010). COSII genetic maps of two diploid Nicotiana species provide a detailed picture of synteny with tomato and insights into chromosome evolution in tetraploid N. tabacum. Theor. Appl. Genet. 120, 809-827.

Wu, F., Mueller, L. A., Crouzillat, D., Pétiard, V., and Tanksley, S. D. (2006). Combining bioinformatics and phylogenetics to identify large sets of single-copy, orthologous genes (COSII) for comparative, evolutionary and systematic studies: a test case in the euasterid plant clade. Genetics 174, 1407-1420.
Yang, B. C., Xia, B. G., Chen, X. J., and Shi, C. H. (2007). Assessing the genetic diversity of tobacco germplasm using intersimple sequence repeat and interretrotransposon amplification polymorphism markers. Ann. Appl. Biol. 150, 393-401.

Yu, Y.-L., and Lin, T.-Y. (1997). Construction of phylogenetic tree for Nicotiana species based on RAPD markers. J. Plant Res. 110, 187-193.

Zhang, H., Chen, H.-T., and Glisin, V. (2003). Isolation of DNAfree RNA, DNA, and proteins by cesium trifluoroacetate centrifugation. Biochem. Biophys. Res. Commun. 312, 131-137.

Zhang, S., and Zaitlin, D. (2008). Genetic resistance to Peronospora tabacina in Nicotiana langsdorffii, a South American wild tobacco. Phytopathology 98, 519-528.

Conflict of Interest Statement: The authors declare that the research was conducted in the absence of any commercial or financial relationships that could be construed as a potential conflict of interest.

Received: 17 May 2012; accepted: 29 July 2012; published online: 24 August 2012. Citation: Zhang S, Gao M and Zaitlin D (2012) Molecular linkage mapping and marker-trait associations with NIRPT, a downy mildew resistance gene in Nicotiana langsdorffi. Front. Plant Sci. 3:185. doi: 10.3389/fpls.2012.00185

This article was submitted to Frontiers in Plant-Microbe Interaction, a specialty of Frontiers in Plant Science.

Copyright (C) 2012 Zhang, Gao and Zaitlin. This is an open-access article distributed under the terms of the Creative Commons Attribution License, which permits use, distribution and reproduction in other forums, provided the original authors and source are credited and subject to any copyright notices concerning any third-party graphics etc. 